\author{
PILAR ANDUEZA UNANUA \\ UNIVERSIDAD DE NAVARRA
}

\title{
La joyería masculina a través de la galería de retratos de virreyes del Museo Nacional de Historia (México)
}

Lo largo del antiguo régimen, ningún monarca español pisó el
Nuevo Mundo. La gran distancia que separaba las tierras americanas
de la Península Ibérica, junto con la incertidumbre y los peligros de una larga travesía, así lo determinaron. Por ello fue necesario gobernar aquellos vastos territorios a través de la figura del virrey, quien en la distancia gozó de gran autonomía, así como de amplias facultades y prerrogativas. Aunque de esta ausencia física del monarca podría haberse derivado un debilitamiento del poder real, no ocurrió así. De hecho, los reyes, aunque desde la lejanía, estuvieron presentes en la vida cotidiana del nuevo continente, valiéndose para ello en gran medida de la fiesta pública. ${ }^{\text {I }}$ Tomando como ejemplo el modelo europeo y barroco - y con un carácter colectivo e integrador-, se desplegó una gran estrategia propagandística e ideológica de carácter festivo que facilitó la presencia simbólica de los reyes en el espacio público novohispano. De este modo, a través de una serie de manifestaciones de lealtad a la Corona, la imagen del monarca se exaltaba a través de arquitecturas efímeras que acogían pinturas, esculturas, jeroglíficos y textos. ${ }^{2}$ Pero a ésta, propia de un calendario festivo extraordinario, se unía habitualmente, tanto en

I. Aunque existen ya numerosos trabajos al respecto, creemos necesario destacar un magnífico estudio sobre la fiesta en la Nueva España: José Miguel Morales Folguera, Cultura simbólica y arte efímero en la Nueva España, Sevilla, Junta de Andalucía, I991.

2. Víctor Mínguez Cornelles, Los reyes distantes: imágenes del poder en el México virreinal, Castelló de la Plana, Universitat Jaume I, I995, pp. 23-28, y "Arte, espectáculo y poder en la 
edificios públicos como privados, la exhibición de retratos del monarca reinante.

Del mismo modo, como máximo representante de la Corona, también la figura del virrey fue muy alabada y ensalzada. Así se comprueba en las ceremonias de entrada en sus respectivas cortes, donde el discurso propagandístico, apoyado en las artes plásticas y la literatura, lograba crear una iconografía de naturaleza mitológica que elogiaba sus virtudes, y por extensión las del rey, convirtiéndose esta imagen en el primer retrato, alegórico en este caso, del nuevo mandatario. ${ }^{3}$ Además, su presencia en aquellos lugares se reforzó a lo largo de su gobierno con algunos otros retratos, tanto pintados como grabados, distribuidos por todo el virreinato, que enaltecían su imagen y daban a conocer a un personaje que - como máximo representante del monarca- poseía un extraordinario poder político, militar y judicial. Y así, determinadas instituciones, corporaciones y congregaciones encargaron su efigie como agradecimiento por la protección o los favores recibidos y la mostraban en sus edificios de representación con gran orgullo. Aunque menos habituales, no faltaron tampoco los retratos alegóricos, donde el virrey aparecía rodeado de las virtudes del buen gobierno, así como otros de carácter devocional o incluso rodeado de su familia en una imagen ya propia del siglo XIX. ${ }^{4}$ Sin embargo, entre todas las tipologías sobresalen aquellos retratos que formaron parte de galerías, no tanto por su calidad artística, de la que a menudo carecían, cuanto por constituir un documento histórico de valor absolutamente excepcional.

\section{Los gabinetes de retratos}

Aunque la idea de conformar gabinetes con retratos de personajes ilustres - ya fueran éstos antiguos o contemporáneos, así como de familiares- hundía sus raíces en la Edad Media, fue durante el Renacimiento cuando esta costumbre se afianzó en las cortes europeas, tal como lo pone de manifiesto, por ejemplo, la colección que formó Felipe II en el Palacio Real de El Pardo, cuya finalidad

fiesta novohispana”, en Herón Pérez Martínez (ed.), México en fiesta, Zamora, El Colegio de Michoacán, 1998, pp. 315-327.

3. Mínguez Cornelles, Los reyes distantes..., op. cit., pp. 31-45; Inmaculada Rodríguez Moya, La mirada del virrey: iconografía del virrey en la Nueva España, Castelló de la Plana, Universitat Jaume I, 2003, pp. 87-90.

4. Rodríguez Moya, op. cit., pp. 94-106. 
no fue otra que realizar una apología de la Casa de Habsburgo. Como indica Portús Pérez, "lo importante era expresar la idea de sucesión y continuidad, que actuaba como legitimadora de poder y como memoria histórica". ${ }^{6} \mathrm{~A}$ imitación de los gabinetes que coleccionaban los monarcas, la nobleza pronto siguió sus pasos destinando un espacio de sus residencias señoriales como salas de linaje, donde colgaban cuadros de sus antepasados, ordenados de acuerdo con ciertas reglas, como fuente de identidad familiar, signo de abolengo y exaltación de la estirpe. A ellos se unían los retratos de los monarcas, en ocasiones para destacar su vinculación con los reyes, pero en general como un acto de lealtad y fidelidad a la Corona. Aquellas pinturas a menudo habían sido regaladas por los propios monarcas y podían incorporar también retratos de otros soberanos europeos, series de emperadores romanos e incluso personajes asiáticos. No faltaron quienes - sin pertenecer a la nobleza, pero ansiando escalar posiciones sociales - participaron de esta dinámica para dotarse de un pasado ilustre inexistente. La práctica de reunir este tipo de colecciones fue habitual en España y se extendió hacia América, adonde llegaban fletes desde Sevilla compuestos por retratos de emperadores romanos y miembros de la familia real.7 Aquellas galerías se convirtieron así en uno de los lugares más importantes del espacio doméstico nobiliario hispánico, no sólo por su magnificencia y riqueza iconográfica y visual, sino también merced a la información que aportaban al visitante sobre el estatus social de quien lo recibía, así como sobre sus gustos y su sensibilidad artística.

Paralelamente, instituciones y corporaciones de diversa naturaleza: comerciales, universitarias, eclesiásticas y políticas, especialmente ayuntamientos, introdujeron también esta costumbre en los edificios oficiales, de modo que las salas de los cabildos, sobre todo municipales y catedralicios, comenzaron a nutrir las paredes con sus principales hombres de gobierno, perpetuando su

5. María Kusche, "La antigua galería de retratos del Pardo: su reconstrucción arquitectónica y el orden de colocación de los cuadros", Archivo Español de Arte, núm. 43, I99I, pp. I-28.

6. Javier Portús Pérez, "Varia fortuna del retrato en España”, en Javier Portús Pérez (ed.), El retrato español. Del Greco a Picasso, Madrid, Museo Nacional del Prado, 2004, p. 40.

7. Juan Miguel Serrera, "Alonso Sánchez Coello y la mecánica del retrato de corte", en Santiago Saavedra (ed.), Alonso Sánchez Coello y el retrato en la corte de Felipe II, Madrid, Museo del Prado, I990, pp. 56-58; Lucía Varela, "El rey fuera de palacio: la repercusión social del retrato regio en el Renacimiento espańol”, en El linaje del emperador, Cáceres, Sociedad Estatal para la Conmemoración de los Centenarios de Felipe II y Carlos V, 2000, pp. 99-I34; Inmaculada Rodríguez Moya, "Los retratos de los monarcas espańoles en la Nueva España", Anales del Museo de América, núm. 9, 200I, pp. 287-288. 
memoria para la posteridad. Y como un reflejo de lo que ocurría en Espańa, este uso se asentó y afianzó también en el Nuevo Mundo, tanto en la Nueva España como en el Perú, así como posteriormente en los virreinatos de Nueva Granada y Río de la Plata.

Concretamente, en las tierras novohispanas proliferaron galerías de retratos en diversos edificios institucionales, como la Catedral Metropolitana de México, que recogió en dos series a sus arzobispos; la Real y Pontificia Universidad, que mandó plasmar a sus rectores y algunos catedráticos y alumnos, o corporaciones civiles como el Real Tribunal del Consulado. No faltaron colegios que reunieron los retratos de sus graduados, o conventos, congregaciones y cofradías que hicieron lo propio con sus integrantes más destacados. ${ }^{8}$ Estas series de cuadros con los miembros más ilustres tenían una finalidad ejemplarizante, pero también se constituían como una muestra de reafirmación de pertenencia a una colectividad. Sin embargo, aquellos gabinetes no fueron los únicos. De hecho, tanto el ayuntamiento de la capital como el palacio de gobierno reunieron sendas galerías con los retratos de los virreyes, acompañados del monarca reinante. Su raíz era propagandística, pues a través del conjunto se hacía presente el poder real, que se prolongaba hasta aquellas tierras y se ejercía por medio de los virreyes, poniendo de relieve además la continuidad dinástica de la monarquía que era la que los nombraba. Pero además tuvo un carácter conmemorativo, pues su finalidad fue también testimoniar la historia, es decir, dejar constancia para la posteridad de quién había gobernado, en nombre del rey, aquellas tierras. ${ }^{9}$ En efecto, el retrato en este caso no sólo lograba perpetuar la memoria del individuo más allá de su muerte física, como era su objetivo, sino que además, al formar parte de una galería, se convertía en una pieza fundamental para la conservación de la memoria histórica colectiva. ${ }^{\text {Io }}$ Pero a ello, como ocurría con el discurso desarrollado en las exequias de aquellos mandatarios, se sumaban también la gratitud y el reconocimiento del virreinato que habían regido con mayor o menor éxito.

8. Rogelio Ruiz Gomar, "La pintura de retrato en la Nueva España”, e Iván Escamilla González, "Verdadero retrato: imágenes de la sociedad novohispana en el siglo xviı", en Beatriz Mackenzie (coord.), El retrato novohispano en el siglo XVIII, Puebla de los Ángeles, Secretaría de Cultura de Puebla, I999, pp. IO-I I y 47-48, respectivamente; Rodríguez Moya, La mirada del virrey..., op. cit., p. 107.

9. Rodríguez Moya, ibidem, pp. I06-I07.

Io. Portús Pérez, op. cit., pp. 24 y 4I. 


\section{La galería de retratos de virreyes del Museo Nacional de Historia de México}

Procedente del antiguo Palacio de los Virreyes de México — actual Palacio Nacional-, el Museo Nacional de Historia, ubicado en el castillo de Chapultepec de la misma ciudad, conserva una galería de retratos de todos los virreyes que gobernaron la Nueva España. Junto a la custodiada en las oficinas del Gobierno del Distrito Federal, constituyen las dos únicas series que han llegado hasta nuestros días en la capital mexicana. ${ }^{I I}$

Al margen de su calidad artística y de la evolución estilística de la pintura, la serie de virreyes expuesta en el Museo Nacional de Historia se erige en un bien cultural de gran magnitud, no sólo como testimonio histórico de primer orden, sino también como un espejo en el que se refleja con nitidez la evolución en las modas, tanto en lo referente a la indumentaria como al adorno personal masculino. ${ }^{\mathrm{I}} \mathrm{Y}$ es precisamente en estos aspectos etnográficos y artísticos, en especial el referido a las joyas, donde queremos centrar nuestro estudio. Lamentablemente son muy escasas las piezas físicas (tanto de indumentaria como de alhajas) que han llegado hasta nuestros días, por lo que la pintura se convierte en herramienta básica para profundizar en su conocimiento. Al contar además con una secuencia que abarca ininterrumpidamente desde el siglo XVI hasta la Independencia mexicana en el siglo XIX, es posible también analizar la evolución de los gustos y las modas tanto en atuendos como en adornos. Al retrato durante el antiguo régimen se le exigió transcribir de manera fidedigna los rasgos físicos del modelo y transmitir los datos básicos para conocer la condición personal del retratado. ${ }^{13}$ Desconocemos si algunos de estos retratos, sobre todo los correspondientes a los siglos XVI y XVII, por su esquema extremadamente repetitivo, lograron el primer objetivo, pero no cabe duda de que los resultados fueron satisfactorios en el segundo aspec-

I I. La galería del Palacio de los Virreyes sufrió un incendio en I692, lo que obligó a rehacer los cuadros. Para ello se siguieron como modelo los retratos del ayuntamiento, hoy en las oficinas del Gobierno del Distrito Federal, tal como apuntan Elisa Vargaslugo, "La pintura de retrato", en Enrique Nieto (coord.), Historia del arte mexicano, México, Salvat, 1986, t. VI, p. 75, e Inmaculada Rodríguez Moya, "El retrato de la élite en Iberoamérica: siglos Xvi a xviII", Tiempos de América, núm. 8, 200I, pp. 8I-82.

I2. Sobre estos aspectos en el ámbito novohispano, especialmente en lo que a vestido se refiere, cabe destacar: José R. Benítez, El traje y el adorno en México. I500-1910, Guadalajara, Imprenta Universitaria, I946, y Abelardo Carrillo y Gariel, El traje en la Nueva España, México, Instituto Nacional de Antropología e Historia, 1959.

I3. Portús Pérez, op. cit., pp. 24-25. 
to, pues los escudos de armas, las cartelas con inscripciones, la indumentaria y las joyas son una fuente de información extraordinaria.

Nos hallamos ante una colección formada por 6I cuadros cuyas medidas superan los $90 \mathrm{~cm}$ de alto y oscilan entre 60 y $75 \mathrm{~cm}$ de anchura. En ellos se repite un esquema similar en el que el retratado aparece de medio cuerpo, levemente girado hacia uno u otro lado, y en todos los casos de pie, excepto en la representación que hizo el pintor José Perovani de Félix María Calleja del Rey en I8I5, donde se muestra sentado en una silla de madera tallada, dorada y tapizada en terciopelo rojo. Otro común denominador en buena parte de ellos resulta la muestra de sus manos, a veces una, a veces las dos, sujetando las instrucciones de gobierno, sustituidas en alguna ocasión por una bengala, como en el caso del marqués de Casafuerte, salido de los pinceles de Juan Rodríguez Juárez, o un bastón de mando en todos los correspondientes al siglo XIX. Los retratados se presentan en lienzo con gran porte y dignidad, repitiendo un esquema en el que se hace presente su escudo de armas en uno de los ángulos superiores, costumbre que desaparece a partir de los años ochenta del siglo xvin, y una cartela en la parte inferior que informa de la identidad del retratado, a veces con sus títulos, y en algunos casos también con la fecha de ejecución. De nuevo, el mencionado retrato de Calleja del Rey resulta excepcional en este sentido, pues la información aparece cincelada sobre un pedestal pétreo.

Al igual que ocurrió en la metrópoli, la llegada de los Borbones al trono español supuso un punto de inflexión radical en la iconografía de reyes, nobles e incluso de la burguesía ennoblecida, merced a la introducción de las modas en el vestido llegadas de Francia. Lógicamente, los virreyes de la Nueva Espańa, adonde arribaban las modas de la metrópoli con gran celeridad, no resultaron una excepción en este sentido. Todos los virreyes de esta galería correspondientes a los siglos XVI y XVII —incluyendo el primero que gobernó en el Siglo de las Luces, Francisco Fernández de la Cueva, duque de Alburquerque - aparecen recortados sobre un fondo monocromo oscuro vistiendo una austera indumentaria negra, propia de los Austrias, pero la influencia francesa se deja sentir con gran fuerza a partir del retrato del duque de Linares, Fernando de Alencastre Noroña y Silva, atribuido a Francisco Martínez y realizado hacia I7I6.* En efecto, nos hallamos ante los típicos retratos oficiales barrocos de aparato, nacidos de la mano de Luis XIV, donde la oscuridad anterior es sustituida

* Véase Anales, vol. XXXIII, núm. 99 [n. del ed.]. 
por un gran cortinaje que ocupa buena parte del fondo del cuadro y donde el colorido y la riqueza de las indumentarias, especialmente los bordados en hilo de oro, así como las pelucas blancas, aportan luz y color a la obra. Son además retratos mucho más individualizados, más realistas, capaces de mostrar desde un duque de Linares elegante y altivo hasta un conde de Fuenclara de aspecto bonachón y amable, pasando por un marqués de Casafuerte de mirada profunda y aun inquisitorial. Pero esta individualización del retratado, impensable en los siglos pretéritos, y la calidad de los lienzos no son casuales. Por el contrario, los retratos fueron realizados por los pintores más afamados del virreinato, como Juan y Nicolás Rodríguez Juárez, José de Ibarra, Miguel Cabrera, Juan Patricio Morlete Ruiz, Pedro de Martínez y Francisco Antonio Vallejo. Con la llegada del academicismo se volvió a los fondos monocromos, lo que, unido a una mayor austeridad en el vestido, desembocó en retratos de mayor sencillez, siendo además de calidad muy desigual. ${ }^{\mathrm{I}}$

\section{La joyería masculina}

Durante los siglos del antiguo régimen, tanto el vestido como la joyería resultaron elementos fundamentales con los que el individuo proyectaba su imagen al exterior. A través de ellos, el portador lograba enviar a la sociedad una información clara y nítida que permitía ubicarlo dentro de la escala económica y social del reino, dado que la adquisición de aquellos objetos estaba limitada a un grupo social reducido y privilegiado y, por tanto, tenía un carácter elitista. Traje y joyas se erigieron así, al margen de su uso práctico, en un código cargado de connotaciones, perfectamente entendido por todos, que ayudaba a conformar y proyectar la apariencia externa del estamento nobiliario. Pero

I4. Un estudio de esta galería de retratos lo hallamos en Rodríguez Moya, La mirada del virrey..., op. cit., pp. I09-229. Con anterioridad y desde un punto de vista catalográfico, puede verse Esther Acevedo de Iturriaga, Catálogo del retrato del siglo XIX en el Museo Nacional de Historia, México, Instituto Nacional de Antropología e Historia, 1982, y Bárbara Meyer y María Esther Ciancas, La pintura de retrato colonial (siglos XVI-XVIII). Catálogo de la colección del Museo Nacional de Historia, México, Instituto Nacional de Antropología e Historia, I994. Sobre los pintores que participaron en la conformación de este gabinete sobresale Bárbara Meyer y María Esther Ciancas, "Los autores que retrataron a los virreyes novohispanos", en Lourdes Herrasti y Bárbara Meyer, El otro yo del rey: virreyes de la Nueva España, I535-I82I, México, Instituto Nacional de Antropología e Historia, 1996. 
a pesar del elevado gasto económico que suponía tal consumo suntuario, éste no fue opcional ni para la nobleza ni para quienes aspiraban a ella. Por el contrario, constituyó una auténtica obligación. No solamente lo exigía su dignidad y rango, sino que además estaba ligado al decoro de su estatus. ${ }^{15}$ Ahora bien, en su utilización concurrieron también en muchas ocasiones otros factores, como el gusto por el lujo, el refinamiento e incluso la ostentación.

En este contexto, las damas contaron con una amplia diversidad de alhajas. Tanto las tipologías como sus diseños fueron transformándose no sólo en relación con los estilos artísticos imperantes, sino también de acuerdo con los cambios de gustos y costumbres, íntimamente unidos además a una evolución paralela de las modas de trajes y peinados. Oro, plata, piedras preciosas, especialmente diamantes y esmeraldas, así como esmaltes y perlas conformaban los materiales principales. Frente a ellos el adorno masculino resultó mucho más limitado y comedido. No obstante, aunque determinadas piezas, como hebillas, botones, gafetes, pasadores, alfileres o gemelos, habían surgido con un sentido eminentemente práctico y utilitario, se tornaron en elementos de adorno y a ellos se sumaron también otras piezas como sortijas, relojes, bandas metálicas o cadenas de variados grosores, sin que faltaran aderezos diversos para sombreros, ricas empuñaduras de bastones y armas, así como variadas guarniciones y adornos en sus caballos y monturas.

Pero entre todas las alhajas masculinas destacaron sobremanera los llamados hábitos o encomiendas, tal como lo ponen de manifiesto numerosos retratos de los siglos XVI, XVII y XVIII, tanto en España como en América, encabezados por los propios reyes que casi siempre dejaban bien visible el Toisón de Oro. Y así se comprueba en buena parte de los retratos custodiados en el castillo de Chapultepec, donde nada menos que 29 virreyes muestran su pertenencia a una orden militar a través de una joya. Pero la exhibición de este tipo de emblemas no era sólo cuestión de adorno, sino que encerraba otro tipo de valores simbólicos. ${ }^{16}$ De hecho, con ellas el portador pregonaba con orgullo ante la sociedad su rango, es decir, su condición nobiliaria, ya fuera ésta de origen remoto o de nueva adquisición, y al mismo tiempo revelaba su carácter

I5. Antonio Álvarez-Osorio, "Rango y apariencia. El decoro y la quiebra de la distinción en Castilla (siglos XVI-XviII)", Revista de Historia Moderna, núm. I7, I998-I999, pp. 264-266.

I6. Sobre su significado puede verse Faustino Menéndez Pidal de Navascués, "Emblemas de la orden de Santiago", en Francisco Javier Campos (coord.), Lux Hispaniarum. Estudio sobre las órdenes militares, Madrid, Real Consejo de Órdenes Militares, 1999, pp. 377-395, especialmente las pp. 380-38I. 
privativo y minoritario, pues mostraba su pertenencia a un muy restringido grupo social de caballeros, como podía ser cualquiera de las órdenes militares que destacaron en España durante la Edad Moderna, y por extensión en los virreinatos, como las órdenes de Santiago, Calatrava, Alcántara, Montesa y, en menor medida, Malta, a las que se uniría ya en el siglo xviı la de Carlos III. Portar el Toisón de Oro sería ya algo absolutamente excepcional.

Lucir una encomienda presuponía legitimidad e hidalguía tanto como limpieza de sangre y de oficios, requisitos indispensables, al menos en teoría, que habían tenido que ser demostrados para el ingreso, así como riqueza, condición no recogida explícitamente en las constituciones de las órdenes, pero recomendable para poder llevar una vida "con ostentación, magnificencia y lucimiento a sus personas y casas". ${ }^{17}$

Este tipo de joyería masculina vivió un especial desarrollo desde el siglo XVII, particularmente con el reinado de Felipe IV, momento a partir del cual la concesión de hábitos se tornó masiva. A los miembros de las viejas familias nobiliarias que habían obtenido este privilegio por la sangre del linaje al que pertenecían se unieron desde entonces, tanto en la metrópoli como en los virreinatos, otros individuos que eran recompensados por los servicios políticos, burocráticos y militares prestados a la Corona, sin que faltasen quienes lo lograban merced a una simple compra. Este giro, propiciado en gran medida por constituir una fuente de ingresos de gran importancia para la Corona, hizo que los reyes tuvieran que mantener un difícil equilibrio entre gratificar a quienes los servían y se destacaban por sus valores personales, elementos no específicos de la nobleza, y mantener el tradicional prestigio de las órdenes, custodiado por el Consejo de Órdenes, que abogaba por premiar exclusivamente el orgullo del linaje, lo que dio lugar a discusiones doctrinales entre los teóricos de la nobleza. ${ }^{18}$

17. Guillermo Lohmann Villena, Los americanos en las órdenes nobiliarias (I529-1900), Madrid, Consejo Superior de Investigaciones Científicas, I947, vol. I, pp. LVI-LVIII; Elena Postigo Castellanos, Honor y privilegio en la Corona de Castilla. El Consejo de las Órdenes y los Caballeros de Hábito en el siglo XVII, Valladolid, Junta de Castilla y León, I988, pp. I33I44; Marion Reder Gadow, "Las órdenes militares en América", en Campos (coord.), op. cit., pp. 397-423.

I8. Postigo Castellanos, op. cit., pp. I I2-I I3 y I I6-I 19. Sobre las órdenes militares en la Edad Moderna, resulta de gran interés L.P. Wright, "Las órdenes militares en la sociedad española de los siglos XVI y XVII. La encarnación institucional de una tradición histórica”, en John H. Elliot (ed.), Poder y sociedad en la España de los Austrias, Barcelona, Crítica, I982, pp. I5-56. 


\section{Los hábitos o encomiendas en la galería mexicana}

La serie completa de retratos de virreyes que se exhibe en el Museo Nacional de Historia de México permite no sólo comprobar la evolución que sufrieron a lo largo de varios siglos las joyas, especialmente los hábitos, sino también acercarnos en gran medida a la cronología de sus modelos y diseños. Paralelamente, otorga la posibilidad de comparar estas alhajas con otras que han llegado hasta nuestros días, así como con los dibujos conservados en diversas colecciones. Sin embargo, dado que no podemos tener acceso físicamente a las piezas reflejadas en las pinturas y que las modas traspasaban el Atlántico en ambas direcciones con celeridad, más difícil resulta determinar los talleres de donde salieron estas alhajas. En nuestra opinión, muchas de ellas — sobre todo los hábitos- debieron de llevarse a la Nueva España por los virreyes como elemento imprescindible de su imagen pública. Pero también pudieron encargar otras allí e incluso adquirir ejemplares ejecutados en otras latitudes. De hecho, no podemos perder de vista la riqueza en metales preciosos de las tierras americanas donde los plateros elaboraron piezas con gran primor, pero tampoco el intenso tráfico comercial de la Nueva España con Asia a través de la nao de China, desde donde llegaron numerosas joyas y técnicas, como ha quedado atestiguado por la documentación y los tesoros hallados en galeones hundidos. ${ }^{19}$

Las encomiendas, también llamadas veneras, entendidas como joyas, se inspiraron en los emblemas textiles que lucían los hábitos de los caballeros durante el medievo, desde donde se trasladaron en los albores de la Edad Moderna a la indumentaria civil, bordándose a veces sobre el pecho, pero generalmente sobre un lateral del ferreruelo. Durante la dinastía de los Austrias, dado que en la indumentaria masculina primó el color negro y su evolución estilística fue muy lenta, ${ }^{20}$ las cruces, especialmente la de Santiago por su color

19. Letizia Arbeteta Mira, "La joyería: manifestación suntuaria de los dos mundos", en Concepción Lopezosa Aparicio (dir.), El oro y la plata de las Indias en la época de los Austrias, Madrid, Fundación ICO, I999, pp. 425-428; "Joyas en el México virreinal: la influencia europea”, en Jesús Paniagua Pérez y Nuria Salazar Simarro, La plata en Iberoamérica, siglos XVI al XIX, México, Instituto Nacional de Antropología e Historia, 2008, pp. 42 I-423; "Influencia asiática en la joyería española. El caso de la joyería india”, en Jesús Rivas Carmona (coord.), Estudios de platería: San Eloy 2009, Universidad de Murcia, 2009, pp. I23-I 46.

20. Afectó sobre todo el área del cuello, donde se pasó por la lechuguilla, la golilla y la valona, y a la cabeza, donde gorras y sombreros sufrieron una gran evolución hasta alcanzar el sombrero de alas. 
rojo, resultaron sumamente visibles. Así puede verse en la galería novohispana donde varios virreyes de los siglos XVI (Luis de Velasco, padre e hijo, y Álvaro Manrique de Zúníga) y xvir (Diego Fernández de Córdoba, Rodrigo Pacheco y Osorio, Lope Díez de Armendáriz, García Sarmiento de Sotomayor, Francisco Fernández de la Cueva, Melchor Portocarrero Lasso de la Vega y José Sarmiento de Valladares) e incluso el que abrió el Siglo de las Luces (Francisco Fernández de la Cueva) lucían bordado el emblema de la orden a la que pertenecían. Pero en el siglo XVI se comenzó también a extender, afianzándose en la centuria siguiente, la costumbre de exhibir el símbolo de aquel privilegio a través de una joya. No significó aquello que el emblema textil quedara desterrado, sino que, por el contrario, durante mucho tiempo ambos símbolos fueron simultáneos, formando parte de la imagen de su portador. Y así se comprueba una vez más en este gabinete de retratos, donde son varios los mandatarios mencionados, concretamente 15 , los que compatibilizan emblemas en su versión textil y metálica.

Durante los siglos XVI y XVII fue costumbre portar estas joyas sobre el pecho, suspendidas de un cordón, ya fuera textil o metálico, sujetas a menudo por medio de pasadores para evitar su balanceo. Fueron los reyes y los infantes quienes impusieron la moda, como se comprueba en los numerosos retratos de Carlos V y de Felipe II que lucen el Toisón de Oro colgando del cuello mediante cordones de tela encarnada o negra o de un collar metálico. Y por emulación, pronto la nobleza hizo lo propio. Ya en el siglo XviII, con la profunda transformación de la estética masculina, los hábitos pasarían a lucirse cosidos o abrochados a un lado de la casaca. ${ }^{21}$

Al margen de su adscripción cronológica, el modelo básico de joya fue una cruz correspondiente a cada una de las órdenes, recortada en metal, oro o plata y esmaltada en el color oportuno (Santiago y Calatrava en rojo, Alcántara en verde, Montesa en rojo y negro y Malta en blanco). Es el caso del ejemplar que luce el caballero de la orden de Calatrava, un retrato de autor desconocido realizado hacia I570-I590, propiedad del Museo del Prado, hoy en la embajada de España en Berna. ${ }^{22}$ De la simplicidad y sobriedad de estos ejemplares

21. Letizia Arbeteta Mira, La joyería española de Felipe II a Alfonso XII en los museos estatales, Madrid, Nerea, I998, pp. 45-50, y El arte de la joyería en la Colección Lázaro Galdiano, Madrid, Caja Segovia, 2003, pp. I66-I68.

22. Mercedes Orihuela, "Retrato de caballero de la orden de Calatrava", en Leticia Ruiz Gómez (ed.), El retrato español en el Prado. Del Greco a Goya, Madrid, Museo del Prado, 2006, pp. 58-59. 
podría derivarse que fue un modelo empleado exclusivamente cuando estos emblemas se tornaron en joyas, es decir, en el siglo xvi. Sin embargo, la galería mexicana demuestra que no fue así y que este tipo estuvo en vigor durante varios siglos. El retrato del virrey Antonio María Bucareli y Ursúa (I77I-I779) lo pone de manifiesto (fig. I). Francisco Antonio Vallejo plasmó en I772 a este mandatario ilustrado luciendo por triplicado el emblema de la orden de Malta a la que pertenecía: uno bordado sobre la chupa y dos sobre el lado izquierdo de su casaca (uno textil y otro metálico). La orden de San Juan de Jerusalén de Malta tenía como emblema una cruz octogonal blanca sobre fondo rojo. ${ }^{23}$ Traspasado al campo de la joyería, la forma más básica del hábito de Malta, tal como hemos avanzado, fue una cruz recortada sobre metal precioso y rematada por una argolla en la parte superior. En ocasiones incorporaba pequeñas flores de lis doradas en los entrebrazos. ${ }^{24}$ Así lo podemos apreciar en un ejemplar del Museo de Artes Decorativas de Madrid, ${ }^{25}$ en el retrato de Lope de Vega, atribuido a Eugenio Cajés, de la Fundación Lázaro Galdiano, ${ }^{26}$ y en el diseño que realizó para alcanzar el grado de maestría Francesch Grifell en I687, tal como figura en los Llibres de Passanties de Barcelona. ${ }^{27}$ Esta tipología perduró y fue usual incluso en el siglo XIx, como se ve en el autorretrato del pintor Luis de la Cruz y Ríos, fechado hacia I830 y conservado en el Museo del Prado. Otra variante de esta misma tipología — cruz recortada y esmaltada en blanco- incorporó una corona como remate superior, tal como la luce Juan José de Austria en su retrato de autor desconocido de la segunda mitad

23. Raúl Lión et al., "Las órdenes militares de caballería", en Campos (coord.), op. cit., pp. II3-I I 4 y I33-I34. Este tipo de cruz era recuerdo de las antiguas ocho lenguas de la orden, así como de las ocho bienaventuranzas que regían su ideal religioso. Aquellas antiguas ocho lenguas provenían de Provenza, Auvernia, Francia, Aragón, Castilla, Italia, Inglaterra y Alemania, origen de los caballeros establecidos en Rodas cuando iniciaba el siglo XIV.

24. Pilar Andueza Unanua, "La cruz de Malta en la joyería española. Imagen y símbolo de nobleza", Filermo, Publicação da Assembleia Portuguesa dos Cavaleiros da Ordem Soberana e Militar de Malta, vol. I2, 2009, pp. 99-I I4.

25. Arbeteta Mira, La joyería española de Felipe II a Alfonso XII..., op. cit., p. I5 I.

26. Alfonso Pérez Sánchez, La pintura española de los siglos XVII y XVIII en la Fundación Lázaro Galdiano, Madrid, Fundación Lázaro Galdiano, 2005, p. 44; Benito Navarrete Prieto, "De poesía y pintura: Lope de Vega retratado por Van der Hamen", Ars Magazine, núm. 6, 2010, pp. 52-64.

27. Francesca Balzan, "Malta Connections as Observed in the Llibres de Passanties of Barcelona”, en Rivas Carmona (coord.), op. cit., p. I55. 

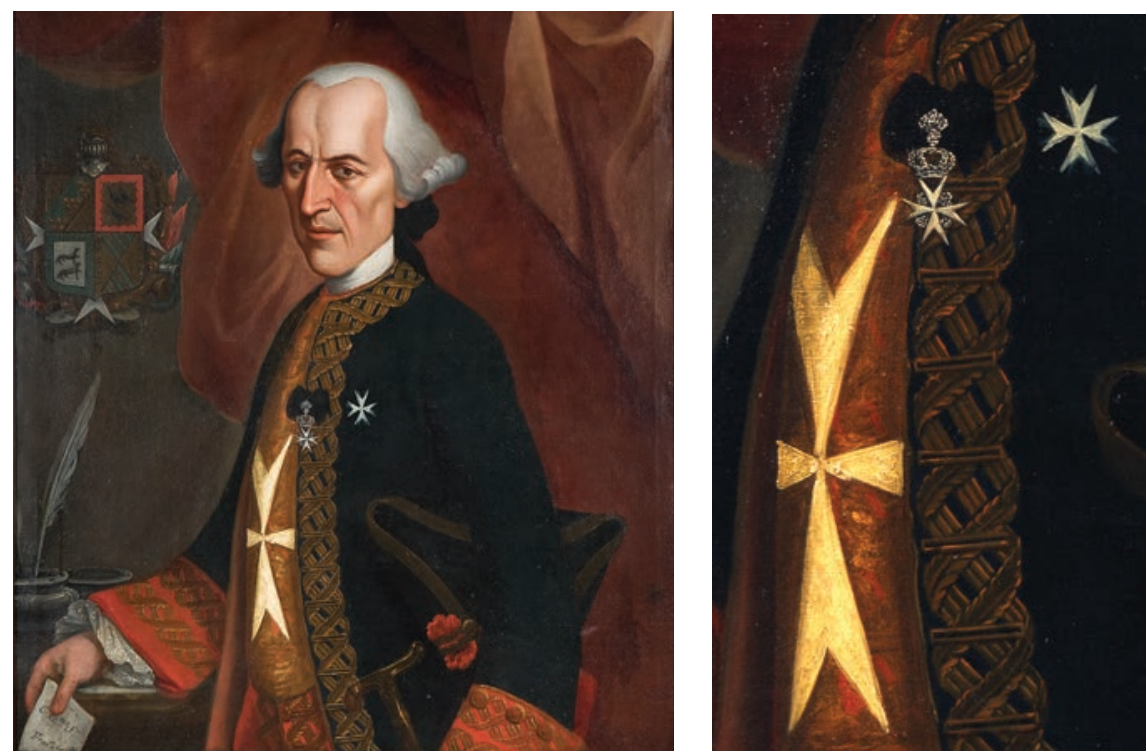

I. Francisco Antonio Vallejo, Antonio María Bucareli y Ursúa, I772, óleo sobre lienzo, $92 \times 73 \mathrm{~cm}$. México, Museo Nacional de Historia. Conaculta-INaH-MÉx. "Reproducción autorizada por el Instituto Nacional de Antropología e Historia”.

del siglo XVII, propiedad del Museo del Prado, ${ }^{28}$ y la volvemos a encontrar en sendos ejemplares recogidos en el Libro de joyas de nuestra señora santa María de Guadalupe. ${ }^{29}$ Avanzado el siglo XviII, este formato todavía seguía en vigor, como se comprueba en el retrato que realizó Anton Rafael Mengs del infante Gabriel de Borbón hacia $1765-1767 .^{30} \mathrm{Y}$ es precisamente este modelo formado por cruz, flores de lis y corona el que hallamos en el retrato de Bucareli, que incorpora también un botón superior para prender la encomienda. Además, parece deducirse del cuadro que estaría montada sobre plata y tanto la corona como el botón estarían cuajados de diamantes.

$\mathrm{Al}$ esquema básico mencionado se unieron en las órdenes militares desde el siglo XVI, prolongándose en la centuria siguiente, cruces recortadas aplicadas

28. Arbeteta Mira, La joyería española de Felipe II a Alfonso XII..., op. cit., pp. 49 y I50.

29. Libro de joyas de nuestra señora santa María de Guadalupe, ed. facs., Guadalupe (España), Ediciones Guadalupe, 2005, f. I6v.

30. Juan J. Luna, "El infante don Gabriel de Borbón (ca. 1765-1767)”, en Ruiz Gómez (ed.), El retrato español en el Prado..., op. cit., pp. I48-I 49. 
sobre veneras de oro o cristal de roca, entendidas ahora como conchas. Así lo demuestran no sólo algunos ejemplares conservados, como el hábito de Malta de la Fundación Lázaro Galdiano, ${ }^{31}$ sino también sendos diseños ofrecidos por Joan Pau y Ioseh Rosell, en I586 y I67 I respectivamente, en los Llibres de Passanties de Barcelona, en ambos casos con la cruz de Santiago, ${ }^{32}$ sin olvidar los retratos de diversas épocas, como el del señor de Alarcón de la mencionada fundación madrileña fechado en la segunda mitad del siglo XVI, ${ }^{33}$ o el del caballero de la orden de Santiago, de José de Ribera, del Museo Meadows de Dallas, cuya cronología nos lleva a mediados de la década de 1630.34 En el caso de la pinacoteca mexicana, hallamos esta tipología en dos lienzos. El primero corresponde al virrey Álvaro Manrique de Zúñiga, marqués de Villamanrique (I585-1590), de I586, de autor desconocido, que no sólo muestra a la perfección la moda en el vestido de la época de Felipe II, sino que además luce una joya con la tipología mencionada colgando de una larga cadena de oro de pequeños eslabones que agarra con su mano derecha. El segundo retrato representa a Rodrigo Pacheco y Osorio, marqués de Cerralbo (I624-I635), fechado en I624, quien, además de mostrar en su indumentaria las modas de la época de Felipe IV con el cambio de la lechuguilla por la golilla y la introducción del sombrero de ala ancha, luce por primera vez entre los virreyes novohispanos otras joyas como son las botonaduras de oro y una banda terciada de gruesos eslabones, que abordaremos en líneas posteriores (fig. 2). El color blanquecino de su venera, labrada en gallones, posiblemente muestra una concha de cristal de roca, que resulta similar a un ejemplar del siglo XviI correspondiente a la orden de Santiago, conservado en el Instituto Valencia de Don Juan. ${ }^{35}$

En la joyería hispana no faltaron tampoco, ya durante el siglo Xvi pero especialmente en el XVII, las cruces de las órdenes militares, bien grabadas, bien recortadas y sobrepuestas, que se aplicaron sobre cabujones de diversos materiales como metales preciosos, cristal de roca, ágata, perlas y azabache,

31. Arbeteta Mira, El arte de la joyería..., op. cit., p. I84.

32. Priscilla E. Muller, Jewels in Spain. I500-I80o, Nueva York, The Hispanic Society of America, 1972, p. II5.

33. Arbeteta Mira, El arte de la joyería..., op. cit., p. I6.

34. Gabriela Finaldi, "Retrato y realidad: Ribalta, Zurbarán, Ribera”, en Portús Pérez (ed.), El retrato español..., op. cit., pp. I46-I55, especialmente la p. I5I.

35. Margarita Pérez Grande, "Venera de la orden de Santiago", en Carmen Iglesias (dir.), El mundo que vivió Cervantes, Madrid, Sociedad Estatal de Conmemoraciones Culturales, 2005 , p. 275 . 

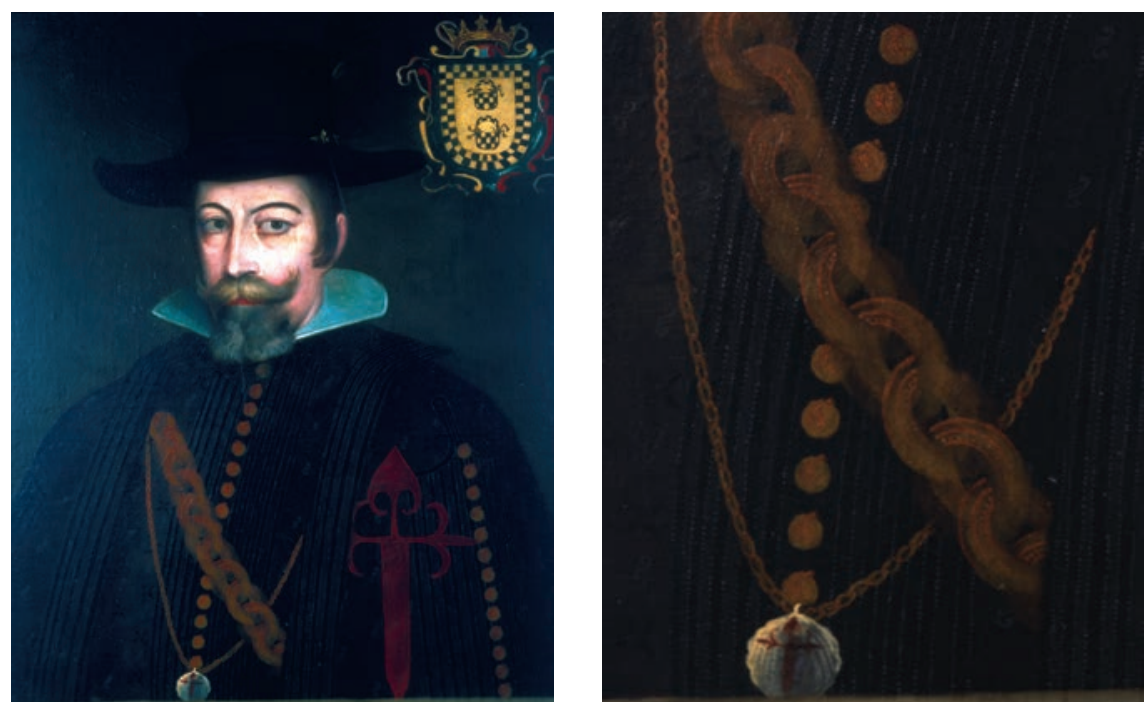

2. Anónimo, Rodrigo Pacheco y Osorio, marqués de Cerralbo, I624, óleo sobre lienzo, $94 \times 70 \mathrm{~cm}$. México, Museo Nacional de Historia. Conaculta-INAH-MÉx. "Reproducción autorizada por el Instituto Nacional de Antropología e Historia”.

e incluso sobre grandes piedras preciosas como esmeraldas y rubíes, según se observa en ejemplares recogidos en el Libro de Guadalupe $e^{36}$ o como lo confirma uno de los que poseyó Calderón de la Barca, montado en este caso sobre una esmeralda. ${ }^{37}$ Podían presentar diversas formas, cercos de mayor o menor sencillez con dentículos, festones, cordones sogueados y escarchados, en ocasiones también esmaltados, así como marcos con diseños más calados por medio de cartones y motivos decorativos con formas de C. Estos últimos, de gusto manierista, se aprecian especialmente en el arranque del siglo XVII. ${ }^{38}$

36. Se trata de sendos hábitos de Calatrava donde la cruz de oro esmaltada se asienta sobre una gran esmeralda. Las piezas fueron regalos de Josefa de Alancaster y del conde del Puerto, respectivamente: Libro de joyas de nuestra señora santa María de Guadalupe..., op. cit., f. 8, núm. 2, y f. I3, núm. I.

37. Letizia Arbeteta Mira, "Espacio privado: la casa de Calderón. Museo del discreto", en Fernando Checa Cremades y José María Díez Borque (coords.), Calderón de la Barca y la España del Barroco, Madrid, Sociedad Estatal España Nuevo Milenio, 2000, pp. 85-86.

38. Arbeteta Mira, La joyería española de Felipe II a Alfonso XII..., op. cit., pp. 47 y I I 8-I I9, y El arte de la joyería..., op. cit., pp. I66-I74. 
Sirvan como ejemplo de esta tipología una magnífica encomienda oval de la orden de Malta conservada en el Instituto Valencia de Don Juan, con aplicaciones de oro recortado y esmaltado, de principios del siglo XVII, ${ }^{39}$ y otra de la orden de Santo Domingo, ligada al Santo Oficio, custodiada en el mismo instituto con cronología similar, de perfil octogonal y labrada en facetas con un cerco biselado y esmaltado en blanco y negro. ${ }^{40}$ La Fundación Lázaro Galdiano también atesora varios ejemplares de este tipo, la mayor parte correspondientes al siglo XVII, y con cerquillos de oro esmaltado en diversos colores. ${ }^{4 \mathrm{I}}$ Los dibujos de la misma época también ratifican estos diseños, como se aprecia en los conservados en el Arxiu Històric de Barcelona que aportan además autoría y cronología, lo que permite verificar las modas vigentes en las primeras décadas del siglo $\mathrm{XVII},{ }^{42}$ y prolongadas en ocasiones a lo largo de aquella centuria, como se ve en el magnífico retrato del duque de Pastrana del Museo del Prado, salido de los pinceles de Juan Carreño de Miranda hacia $1666 .{ }^{43}$ Sobre su atuendo negro centellean el metal de la empuñadura y cazoleta de su espada, la hebilla del cinturón, un pasador y, lo más importante para nosotros, los reflejos cristalinos de su venera de Santiago. ${ }^{44}$

Precisamente al siglo XVII corresponden dos retratos novohispanos que muestran esta tipología. No obstante, la escasa calidad de los lienzos no permite determinar los materiales sobre los que se asentó la correspondiente cruz. Luis Enríquez de Guzmán, conde de Alba de Aliste (1650-I653), en su retrato realizado por autor desconocido hacia 1650 , luce un joyel romboidal, quizá de cristal de roca o azabache, donde se inscribe la cruz de Alcántara (fig. 3). Presenta un cerco de oro esmaltado alternativamente en rojo y blanco. La pieza pende de un cordón textil negro colocado alrededor del cuello y ceñido a éste por debajo de la golilla a través de un pasador o botón esférico de oro, decorado también con pequeños detalles esmaltados y, por tanto, haciendo juego

39. Margarita Pérez Grande, "Insignia de la orden de Malta", en Iglesias (dir.), op. cit., pp. 274-275.

40. Arbeteta Mira, "La joyería: manifestación suntuaria de los dos mundos”, en Lopezosa Aparicio (dir.), op. cit., pp. 439 y 705 ; Margarita Pérez Grande, "Insignia de la orden de Santo Domingo", en Iglesias (dir.), op. cit., p. 501.

4I. Arbeteta Mira, El arte de la joyería..., op. cit., pp. I69-174.

42. Arbeteta Mira, La joyería española de Felipe II a Alfonso XII..., op. cit., p. 47, y El arte de la joyería..., op. cit., p. I67; Balzan, op. cit., pp. I52-I55.

43. Alfonso Pérez Sánchez, "Velázquez y el retrato barroco", en Portús Pérez (ed.), El retrato español..., op. cit., pp. I66-199, especialmente las pp. 197 y 348-349.

44. Así lo hizo ver ya Arbeteta Mira, El arte de la joyería..., op. cit., p. I67. 
3. Anónimo, Luis Enríquez de Guzmán, conde de Alba de Aliste, ca. I650, óleo sobre lienzo, $93 \times 67 \mathrm{~cm}$. México, Museo Nacional de Historia. Conaculta-INAH-MÉX.

"Reproducción autorizada por el Instituto Nacional de Antropología e Historia”.

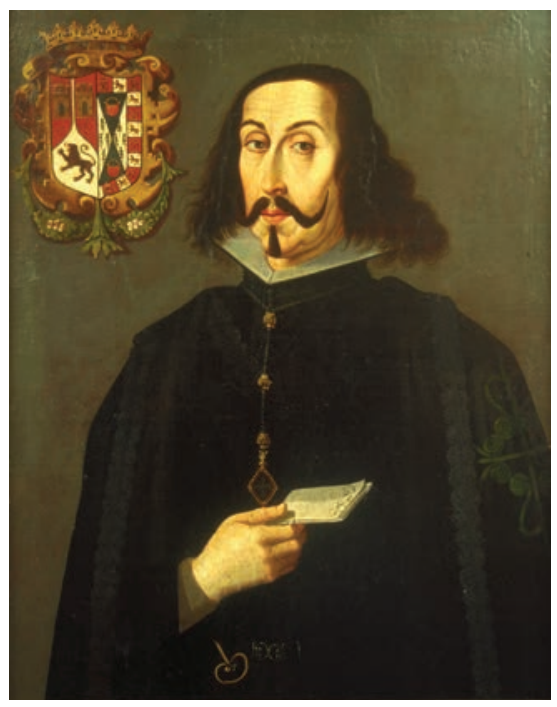

con el hábito. Le siguen más abajo otras dos piezas similares, quedando de este modo el collar totalmente sujeto, centrado y marcando una línea de simetría. La misma tipología la volvemos a encontrar en su sucesor, Francisco Fernández de la Cueva, duque de Alburquerque (I653-I660), bajo cuyo gobierno se consagró la Catedral Metropolitana de México. En su caso, la encomienda es un pieza de oro de buen tamańo y grosor, de perfil octogonal, quizá de filigrana, sobre cuyo campo destaca la cruz de Santiago esmaltada. La acompañan, para ceñir la cinta, tres botones también de oro, esféricos y lisos (fig. 4).

Pero paralelamente a los modelos descritos, las cruces correspondientes a los hábitos y en general toda la joyería, poco a poco — conforme avanzaba el siglo XVII y sobre todo en el XviII, en el ámbito de aquella cultura barroca tan visual-, fueron sufriendo las consecuencias del gusto por la apariencia, la magnificencia y la suntuosidad. Y así, aquellos objetos de lujo fueron ganando en aparato, enriqueciéndose y adornándose con marcos de diseños variados, en unas ocasiones con cresterías de filigrana, barata y efectista, y en otras de oro y plata cincelada con abundantes piedras preciosas, incorporando progresivamente, para sustituir a las sencillas argollas anteriores, copetes formados por botones, lazos e incluso coronas. ${ }^{45}$ Así puede verificarse

45. Sobre esta evolución puede verse Arbeteta Mira, La joyería española de Felipe II a Alfonso XII..., op. cit., pp. 45-50, y El arte de la joyería..., op. cit., pp. I66-I67. 


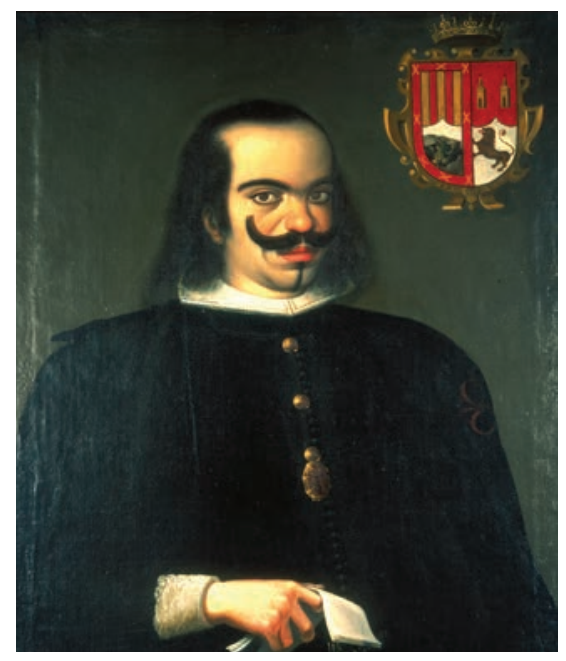

4. Anónimo, Francisco Fernández de la Cueva, duque de Alburquerque, ca. 1653I660, óleo sobre lienzo, 94×66 cm. México, Museo Nacional de Historia. ConacultaINAH-MÉX. "Reproducción autorizada por el Instituto Nacional de Antropología e Historia”.

con nitidez en las joyas de este tipo correspondientes a las órdenes militares recogidas en el Libro de Guadalupe ${ }^{46}$ o en los dos libros de joyas de los exámenes de plateros de Sevilla, custodiados en el archivo de su palacio arzobispal. ${ }^{47} \mathrm{Y}$ otro tanto ocurre con las piezas conservadas en tesoros marianos como el de la Virgen de Gracia de Carmona. ${ }^{48}$ Por su parte, la colección de retratos del Museo Nacional de Historia de México permite comprobar además, a partir de la segunda mitad del siglo XviI, la estrecha relación entre los diseños de los hábitos y las joyas de pecho que lucían las damas, así como la importancia que progresivamente fue adquiriendo en la joyería masculina, de manera paralela a la femenina, el motivo del lazo. Varios lienzos de la colección evidencian ambos elementos. El primero es el correspondiente a Antonio Sebastián de Toledo Molina y Salazar, marqués de Mancera (I664-I672), obra realizada hacia I664 (fig. 5). El virrey, que muestra un rostro muy realista y despierto, luce una joya de oro de diseño cuadrilobulado que acoge la cruz de Alcántara pintada sobre placa esmaltada blanca tam-

46. Libro de joyas de nuestra señora santa María de Guadalupe..., op. cit., ff. 5v, 6v, 8 y I3.

47. María Jesús Sanz Serrano, Antiguos dibujos de la platería sevillana, Sevilla, Diputación Provincial, I986, pp. 27 y I26-I27 y figs. 2 y 72.

48. María Jesús Sanz Serrano, "El tesoro de la Virgen de Gracia de Carmona", en José María Carmona Domínguez (ed.), La Virgen de Gracia de Carmona, Carmona, Hermandad de Nuestra Señora la Santísima Virgen de Gracia, I990, pp. 89, 92, 94 y I I 2-I I5. 

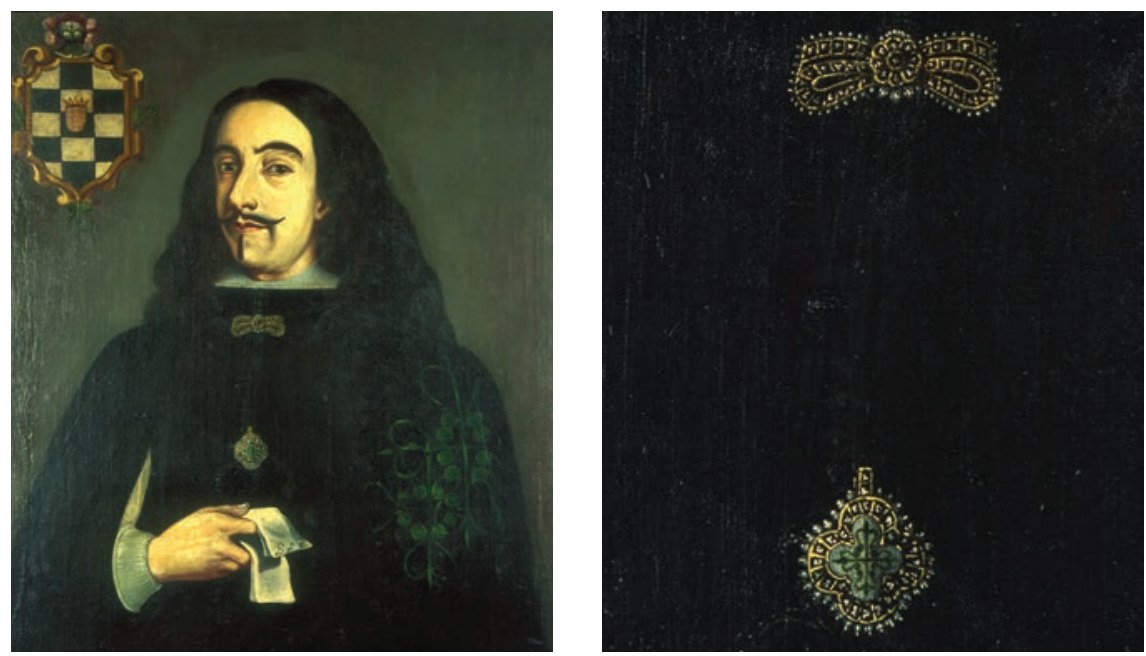

5. Anónimo, Antonio Sebastián de Toledo Molina y Salazar, marqués de Mancera, ca. I664, óleo sobre lienzo, $93 \times 69 \mathrm{~cm}$. México, Museo Nacional de Historia. Conaculta-INAH-MÉx. "Reproducción autorizada por el Instituto Nacional de Antropología e Historia".

bién cuadrilobulada, con orilla dividida en celdillas rectangulares que inscriben diamantes talla-tabla, esquema que se repite en el asa. El perfil está recorrido por una cenefa de perlas que le otorga un ritmo sinuoso y quebrado. Sigue un modelo ya vigente en España hacia I630 y el ejemplar guarda claras analogías con una venera doble de Santiago y Calatrava perteneciente a la archicofradía de la Virgen del Rosario de Antequera (Málaga). ${ }^{49}$ Pende la alhaja de un cordón negro pero, a diferencia de los casos anteriores, ahora los pasadores de botón han sido sustituidos por un lazo, llamado corbata, que queda centrado bajo la golilla. Nuevamente de oro y diamantes, se trata de un lazo encrespado de doble lazada en torno a una rosa central, de la que cuelgan tres pequeñas perlas a modo de pinjantes. Repite el mismo diseño de celdillas y diamantes-tabla y remates en perlas.

A la misma orden militar pertenecieron también Tomás Antonio de la Cerda y Aragón, conde de Paredes (I680-I686), y sus sucesores en el cargo: Melchor

49. Letizia Arbeteta Mira, "Las joyas en el retrato virreinal: una aproximación a su estudio", en Jesús Paniagua Pérez y Nuria Salazar Simarro (coords.), Ophir en las Indias. Estudios sobre la plata americana. Siglos XVI-XIX, León (España), Universidad de León, 20IO, pp. 47-48. 

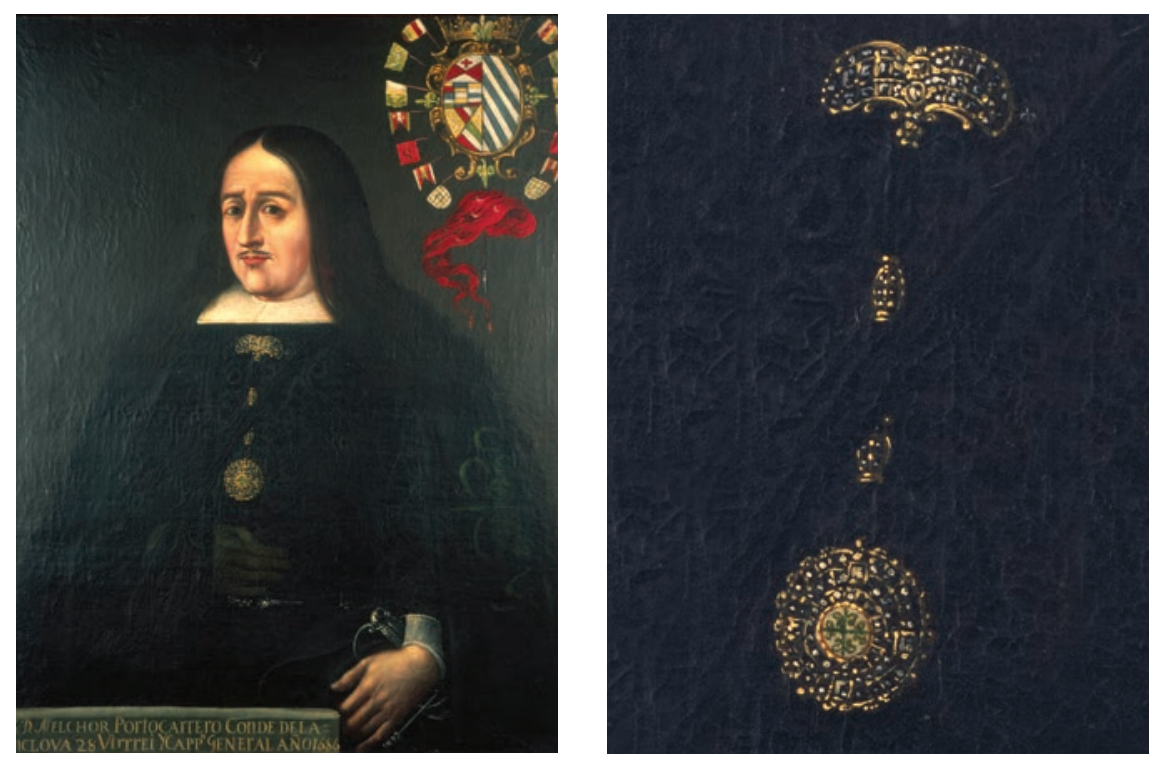

6. Anónimo, Melchor Portocarrero y Lasso de la Vega, conde de la Monclova, ca. I686, óleo sobre lienzo, $93 \times 73 \mathrm{~cm}$. México, Museo Nacional de Historia. Conaculta-InAH-MÉx. "Reproducción autorizada por el Instituto Nacional de Antropología e Historia".

Portocarrero y Lasso de la Vega, conde de la Monclova (I686-I688), y Gaspar de la Cerda Sandoval Silva y Mendoza, conde de Galve (I688-I696), que vuelven a lucir hábitos de la misma tipología, con amplios marcos enriquecidos con pedrería. El más interesante y de mayor tamańo es el que exhibe Portocarrero y Lasso de la Vega, que se asemeja en gran medida a las rosas de pecho femeninas contemporáneas (fig. 6). De perfil circular quebrado, tres bandas de diamantes-tabla montados en oro orlan la placa central esmaltada donde se inscribe la cruz de Alcántara. A juego con estas encomiendas se disponen asimismo en los tres casos un lazo bajo la golilla y varios pasadores de botón. No obstante, la principal diferencia entre estas joyas, todas ellas con labor de engastería de diamantes, radica en el diseńo de los lazos, pues el conde de Paredes presenta un ejemplar con cuatro puntas de cabos rectos, de tipo mariposa, muy geométricos; el conde de la Monclova, uno de diseño arriñonado en torno a dos chatones centrales, y el conde de Galve uno mucho más evolucionado de cuatro lazadas con un diseño extraordinariamente abierto. A medio camino entre estos dos últimos se situaría el diseño de las hebillas de zapatos que luce el niño Joaquín 

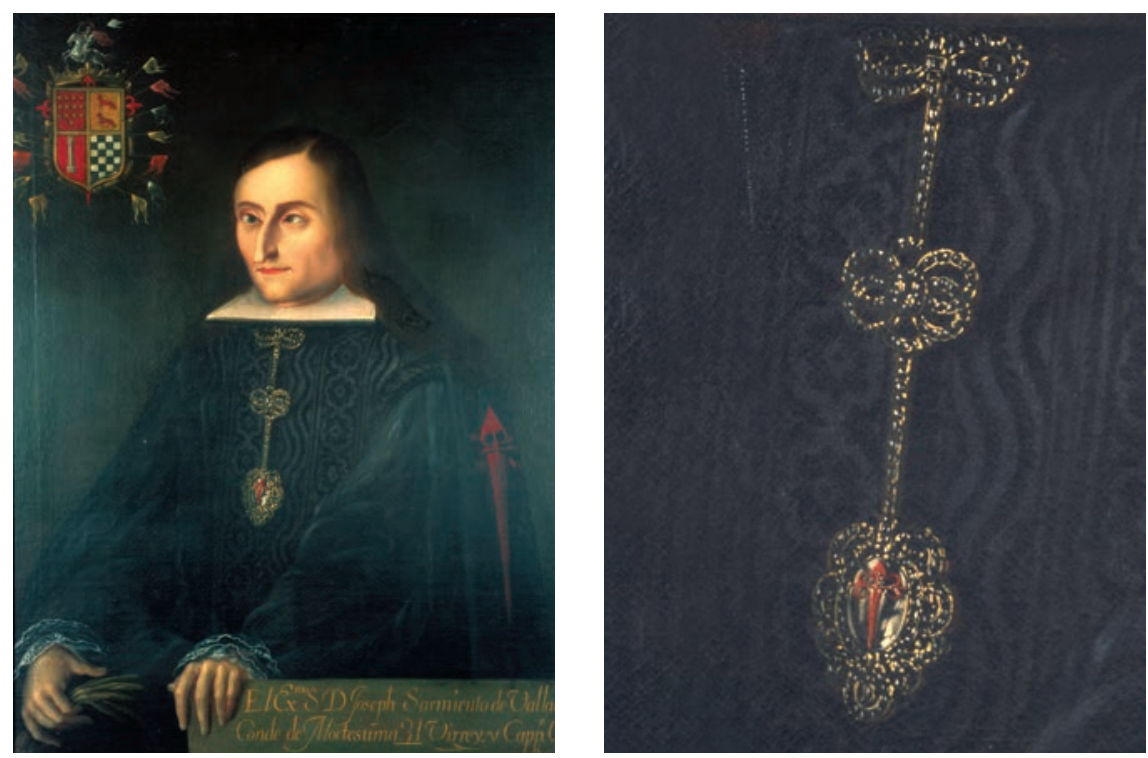

7. Anónimo, José Sarmiento de Valladares, conde de Moctezuma y Tula, ca. I697, óleo sobre lienzo, $94 \times 73 \mathrm{~cm}$. México, Museo Nacional de Historia. Conaculta-InAH-MÉx. "Reproducción autorizada por el Instituto Nacional de Antropología e Historia".

Manuel Fernández de Santa Cruz en su retrato realizado por Nicolás Rodríguez Juárez en 1695, exhibido en el Museo Nacional de Arte (México).

La sucesión cronológica de estos lazos no sólo pone de manifiesto el progresivo naturalismo que van adquiriendo estas piezas, sino que además se enlaza estilísticamente con los diseños de finales del siglo xviı recogidos en el primer libro de joyas de exámenes de plateros de Sevilla ${ }^{50}$ y con las modas femeninas de aquellas fechas como se ve, por ejemplo, con el gran lazo que luce en el pecho Nicolasa Manrique de Mendoza, obra de Claudio Coello realizada hacia I690-I692.

Por su parte, el virrey que cerró el siglo Xviı en la Nueva España, José Sarmiento de Valladares, conde de Moctezuma y Tula (I696-I70I), ofrece la versión más efectista de esta tipología a la vez que avanza la riqueza de lo que será la joyería en la primera mitad del Siglo de las Luces (fig. 7). En efecto, su hábito constituye una joya de gran tamaño, de diseño acorazonado, con la cruz de Santiago recortada y esmaltada sobre cristal de roca y marco de

50. Sanz Serrano, Antiguos dibujos..., op. cit., pp. 24-27 y fig. 2. 
gran desarrollo cuajado de diamantes. Pero frente a los ejemplares anteriores, y siguiendo una moda que comenzó a imponerse al declinar el siglo Xvir, el cordón negro se sustituyó por un ramal metálico rígido de oro, también con piedras engastadas, que no sólo se decora con el lazo bajo el cuello, sino que además incorpora un segundo lazo, de triple lazada, a mitad del pecho, el cual sustituye a los pasadores de botón. Nos hallamos ante una de las joyas de más aparato de toda la galería de retratos, que contrasta poderosamente con la fisonomía del retratado, muy poco agraciado y nada idealizado. No obstante, este tipo de joya pendiente de un eje metálico rígido, único en este gabinete, no alcanza la riqueza de otros ejemplares conocidos en la actualidad, como la extraordinaria venera de Calatrava que recoge el Libro de Guadalupe, regalada por Juan Francisco Clareboutt, fechada, en opinión de Arbeteta, en los ańos ochenta del siglo xviı, o la de Santiago, que exhibe José de Armendáriz, marqués de Castelfuerte y virrey del Perú (I724-I736), en el retrato atribuido a Cristóbal Daza y conservado en el Museo Nacional de Arqueología, Antropología e Historia del Perú. ${ }^{\text {II }}$ Si se compara el retrato del conde de Moctezuma del castillo de Chapultepec con el que se custodia en las oficinas del Gobierno del Distrito Federal, sin duda de mejor calidad, se puede apreciar que luce la misma encomienda. Sin embargo, en el caso del cuadro de la colección municipal, el hábito cuelga de un cordón textil que se decora con un lazo bajo la golilla y dos pasadores de gran tamaño y abundante decoración con diamantes, lo que permite concluir que todas estas piezas eran totalmente desmontables e intercambiables y su uso, por tanto, polivalente.

Aunque Francisco Fernández de la Cueva (1702-I710), entre cuyos numerosos títulos nobiliarios figuró el ducado de Alburquerque, fue el primer virrey civil que gobernó bajo el reinado de los Borbones, su retrato ofrece una imagen todavía ligada a los Austrias, tal como se aprecia en su indumentaria y en sus alhajas (fig. 8). Viste de negro con golilla blanca y, aunque se adorna con una joya que no ofrece novedades en cuanto a su tipología - una encomienda que cuelga de un cordón textil y un pasador de lazo bajo el cuello-, aporta un nuevo paso en la evolución. En efecto, la cruz esmaltada de Santiago, montada con abundantes diamantes sobre oro, presenta un marco con estructura crucífera con hojas polilobuladas de gran desarrollo en los entrebrazos. Este retrato supone también el fin de esta tipología de encomiendas.

5I. Arbeteta Mira, “Las joyas en el retrato virreinal...”, en Paniagua Pérez y Salazar Simarro (coords.), op. cit., p. 48. 
8. Nicolás Rodríguez Juárez, Francisco Fernández de la Cueva, duque de Alburquerque, ca. I708, óleo sobre lienzo, $93 \times 70 \mathrm{~cm}$. México, Museo Nacional de Historia. Conaculta-INAH-MÉx. "Reproducción autorizada por el Instituto Nacional de Antropología e Historia”.

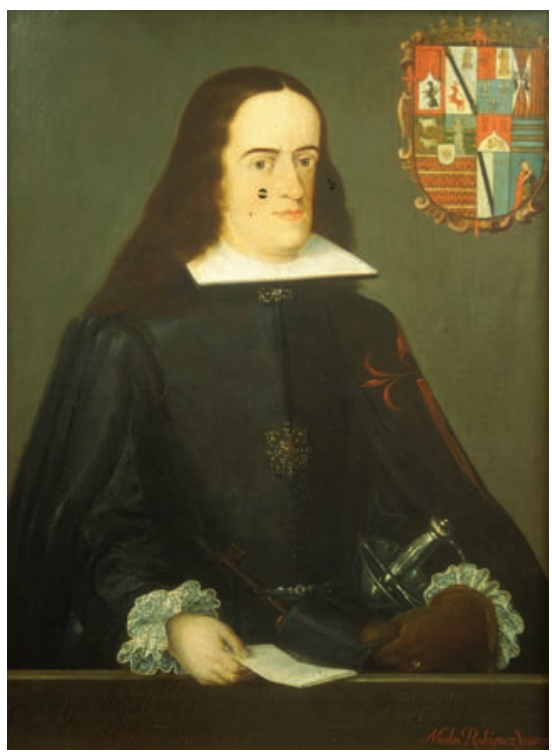

A partir de este virrey, todos sus homólogos correspondientes a los siglos XVIII y XIX muestran en sus retratos no sólo el cambio en el vestido por la imposición de la elegante y colorida etiqueta francesa, sino también en las encomiendas, que modifican tanto su morfología como su ubicación sobre el traje. El retrato del duque de Linares (I7II-I7I6) ofrece un magnífico estudio de calidades, plasmado especialmente en su casaca de color granate bordada en hilo de plata bajo la que asoman las finas puntillas de la corbata y los puños. Precisamente por esta riqueza llama la atención que apenas se distinga su encomienda, que se percibe muy tímidamente y sin detallismo alguno bajo las chorreras de la camisa. Por el contrario, en el magnífico retrato de cuerpo entero que le pintó Juan Rodríguez Juárez hacia I7I7, custodiado en el Museo Nacional de Arte, luce un magnífico hábito que cuelga de una cinta de seda roja dispuesta a la altura del estómago. Como es habitual en estas fechas, muestra una joya que sigue diseños heredados del siglo XVII poniendo de manifiesto el gusto por las piezas grandes, pesadas, con labores de cincelado y calado y multitud de piedras engastadas. De hecho, presenta una estructura similar a las joyas de pecho femeninas de la segunda mitad de aquella centuria que, como este hábito, se componían de un copete o un lazo - en este caso de lazada sencilla y cabos caídos- y la rosa o joya propiamente dicha. 


$$
64
$$
PILAR ANDUEZA UNANUA

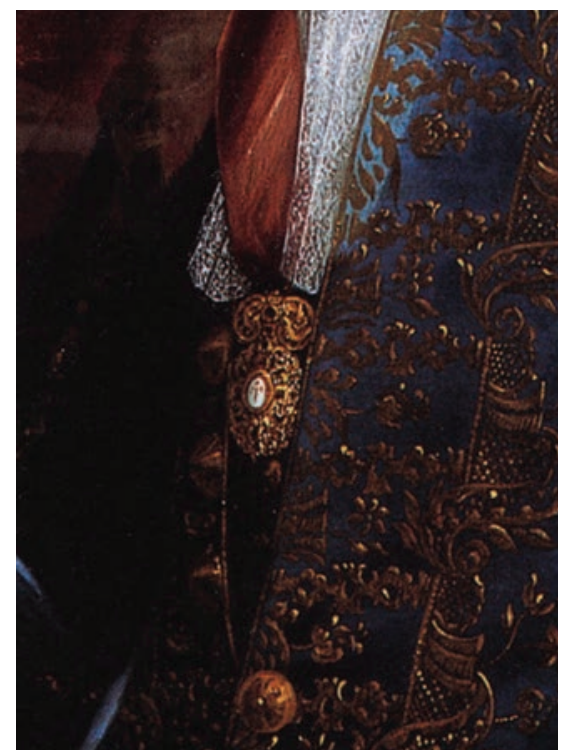

9. Juan Rodríguez Juárez, Fernando de Alencastre Noroña, duque de Linares, detalle, ca. I717, óleo sobre lienzo, $208 \times$ I2 $8 \mathrm{~cm}$. México, Museo Nacional de Arte. "Reproducción autorizada por el Instituto Nacional de Bellas Artes y Literatura, 20I2".

Ésta presenta una estructura levemente oval con la cruz de Santiago pintada sobre placa esmaltada en blanco. Queda encuadrada por un grueso marco de oro con diamantes engastados, si bien la pintura no permite concretar más su diseño, posiblemente de motivos vegetales (fig. 9). Es muy probable, además, que el reverso de la joya estuviera esmaltado con motivos florales y tonos pastel sobre fondo blanco, azul o rosa, siguiendo una moda francesa que se había comenzado a imponer a partir de 1650.52

Con el marqués de Casafuerte, Juan de Acuña (1722-I734), se produce un cambio fundamental. La venera se luce ya definitivamente sobre el lado izquierdo de la casaca, y será ahí donde avanzando el tiempo se colocarán las placas y condecoraciones civiles y militares. Juan Rodríguez Juárez plasmó en este retrato una encomienda de Santiago, pendiendo de un ojal, de perfil oval, montada sobre oro, con orla y marco de abundante hojarasca y pedrería..$^{53} \mathrm{De}$

52. Letizia Arbeteta Mira, "Precisiones iconográficas sobre algunas pinturas de la colección del Museo de América, basadas en el estudio de la joyería representada", Anales del Museo de América, núm. I5, 2007, pp. I49-I50.

53. El Museo de América de Madrid conserva un retrato de este virrey de características iconográficas muy similares. Sin embargo, la venera que luce resulta más pequeña, pende de una cadenita y en torno a su centro esmaltado se dispone una orla de piedras, probablemente 

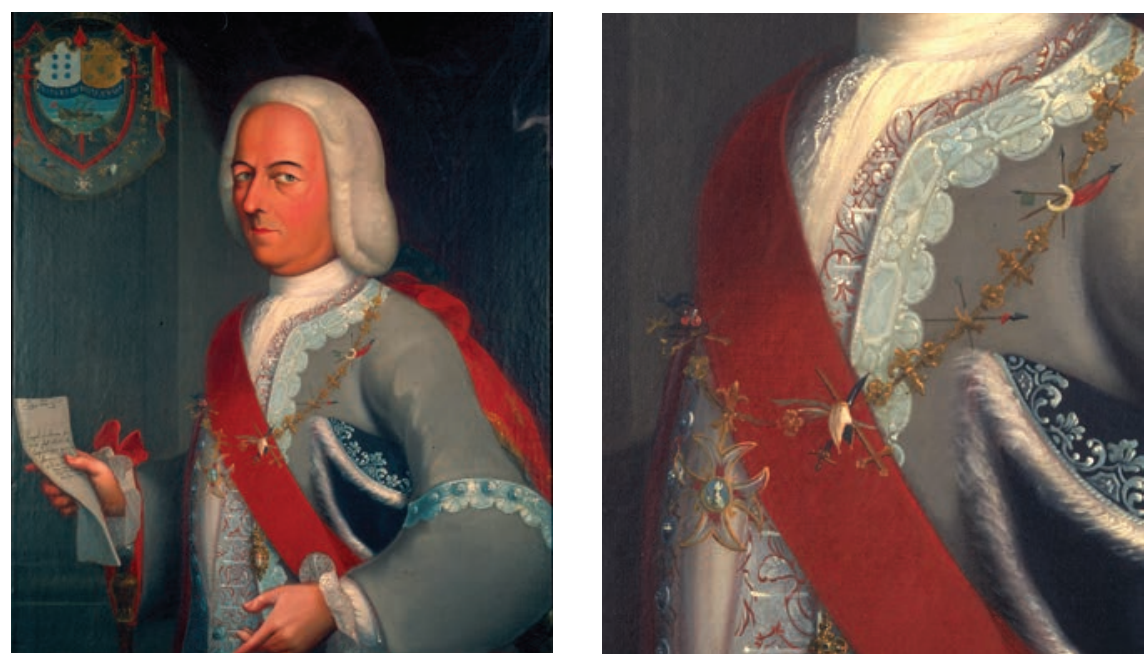

Io. José de Ibarra, Pedro de Castro Figueroa y Salazar, duque de la Conquista, I740-I74I, óleo sobre lienzo, $93 \times 7 \mathrm{I} \mathrm{cm}$. México, Museo Nacional de Historia. Conaculta-Inah-MÉx. "Reproducción autorizada por el Instituto Nacional de Antropología e Historia".

características muy similares es la encomienda oval que ofrece Pedro de Castro Figueroa y Salazar, duque de la Conquista (I740-I74I), si bien presenta tanto el lazo como la joya con la cruz de Santiago, tiene un aspecto mucho más ligero y dinámico, siguiendo una tendencia que triunfará en las décadas centrales del siglo xviıI, como se ve en el diseño realizado por Gabriel Bessa y Sircuns en I748, correspondiente a los Llibres de Passanties de Barcelona ${ }^{54}$ o el dibujo número I del segundo libro de joyas de los exámenes de los plateros sevillanos. ${ }^{55}$ Mucho más llamativa por su gran tamaño resulta la cruz de san Jenaro que el duque de la Conquista luce sobre el pecho. Esmaltada en blanco con llamas en rojo y con la imagen del mártir en el centro, cuelga de su correspondiente collar de hombros (fig. Io). Pero a diferencia del que muestra su sucesor, el conde de Fuenclara, al que nos referiremos en líneas posteriores, en este ejemplar, pintado por José de Ibarra, se introduce el esmalte en algunos eslabones formados por mitras, palmas o banderas.

diamantes, rodeada de un marco con roleos: Arbeteta Mira, "Precisiones iconográficas sobre algunas pinturas...", op. cit., p. I49.

54. Véase Muller, op. cit., p. I6I.

55. Sanz Serrano, Antiguos dibujos..., op. cit., p. I26, lám. I. 

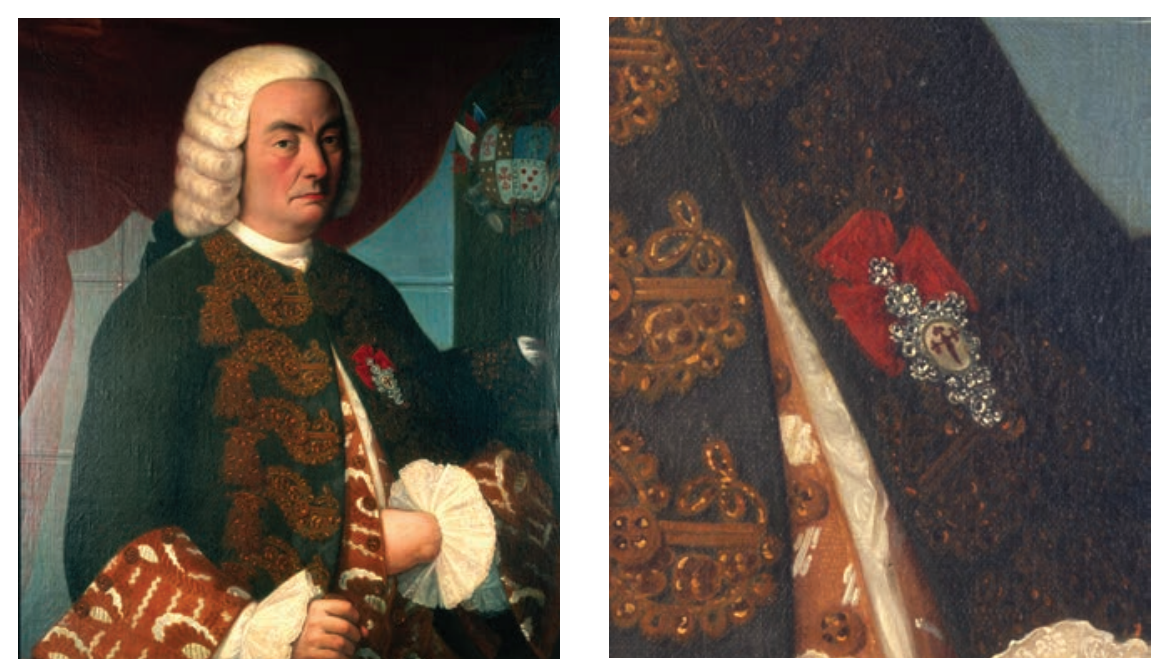

I I. Juan Patricio Morlete Ruiz, Agustín de Ahumada y Villalón, marqués de las Amarillas, I756, óleo sobre lienzo, $97 \times 75 \mathrm{~cm}$. México, Museo Nacional de Historia. Conaculta-INAH-MÉx. "Reproducción autorizada por el Instituto Nacional de Antropología y Historia”.

Casi todos los virreyes de la segunda mitad del siglo XviII portan veneras que siguen una tipología similar basada en una placa central de esmalte con marco de mayor o menor desarrollo en tamaño y decoración. Siempre colocadas sobre el lado izquierdo de la casaca, se exhiben colgando de un lazo de tela cuyo color se relaciona con la correspondiente orden militar. Dado que la pintura no nos permite descender a una descripción minuciosa y detallada, hemos optado por destacar las veneras que a nuestro juicio resultan más sobresalientes. Entre ellas se encuentran la de Agustín de Ahumada y Villalón, marqués de las Amarillas (I755-1760), la correspondiente a Joaquín Juan de Montserrat y Cruillas, marqués de Cruillas (1760-1766), y la de Martín de Mayorga (1779-1783).

El marqués de las Amarillas —retratado por Juan Patricio Morlete Ruiz en I756 - luce la cruz de Santiago sobre una placa oval esmaltada con cerquillo de oro montada sobre un marco triangular de perfil quebrado y recortado formando elementos vegetales y florales totalmente engastados de pedrería, coronada por dos botones con forma de roseta floral, muy del gusto barroco dieciochesco (fig. II). De tamaño similar es la encomienda de la cruz de Montesa del marqués de Cruillas, quien se hace acompañar del mismo emblema 
I2. Pedro de Martínez, Joaquín Juan de Montserrat, marqués de Cruillas, 1761, óleo sobre lienzo, $95 \times 74 \mathrm{~cm}$. México, Museo Nacional de Historia. Conaculta-INAH-MÉX.

"Reproducción autorizada por el Instituto Nacional de Antropología e Historia”.

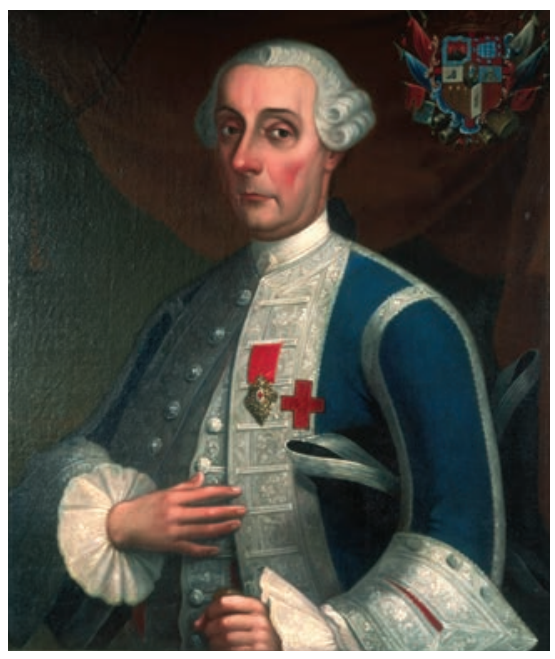

textil ubicado sobre las pasamanerías y bordados plateados de su casaca. La joya con un esmalte central presenta un marco romboidal de oro más compacto y abigarrado que el anterior, pero nuevamente con diamantes engastados (fig. I2). Finalmente, Martín de Mayorga ofrece una alhaja típica del reinado de Carlos III donde el barroquismo ha dado paso a la elegancia, la depuración y el refinamiento. Labrada en plata, con esmalte central que acoge la cruz de Alcántara, presenta perfil circular con orla de guirnalda rodeada de un marco cuajado de diamantes. El copete ha adoptado la forma de corona imperial y botón superior (fig. I3).

Tres fueron los virreyes que en la segunda mitad del Siglo de las Luces destacaron con orgullo su pertenencia a la Real y Distinguida Orden Espańola de Carlos III, fundada por decreto del ig de septiembre de I77I y aprobada por Clemente XIV el 2I de febrero de 1772. Bernardo de Gálvez y Madrid (I785-I786) fue el primer mandatario en hacerlo y a él le siguieron Juan Vicente de Güemes Pacheco y Horcasitas, segundo conde de Revillagigedo (1789-I794), y Miguel de la Grúa Talamanca, marqués de Branciforte (I794-I798). Los tres portan la insignia de acuerdo con lo estipulado en sus constituciones. Como era preceptivo, se trata de un emblema de oro con forma de cruz griega de ocho puntas, con los brazos esmaltados en azul con filetes en blanco rematados por bolas en los extremos. El óvalo central cobija la imagen de la Inmaculada Concepción bajo cuyo patrocinio se hallaba la 

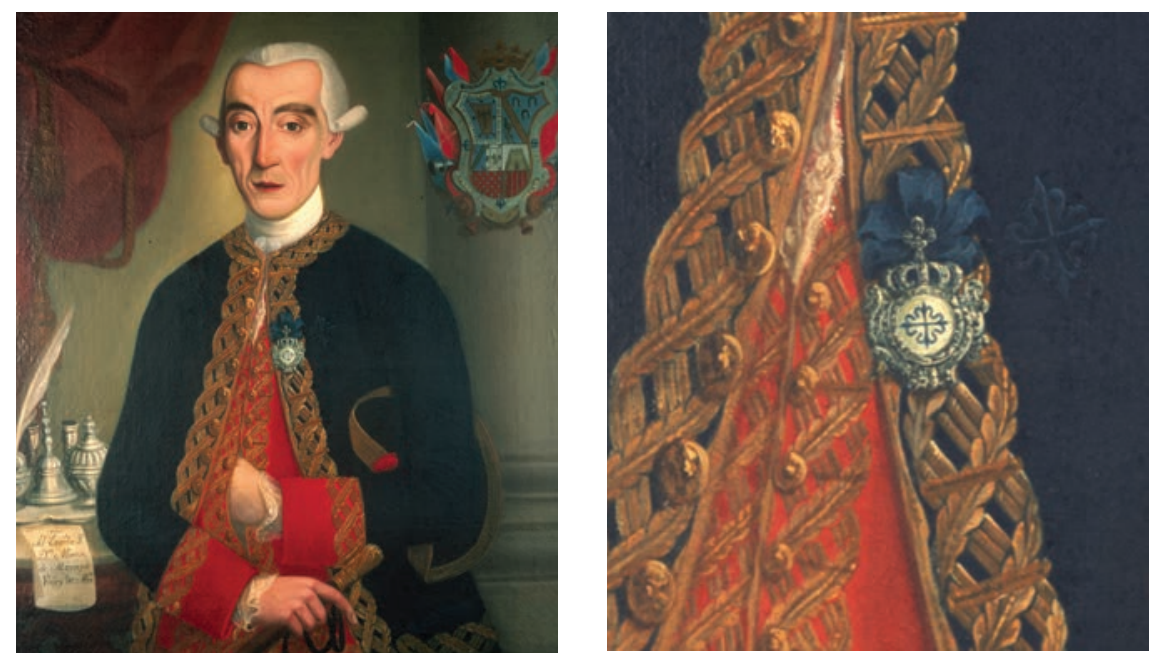

I3. José Germán de Alfaro (atribuido), Martín de Mayorga, ca. I779, óleo sobre lienzo, $92.5 \times 75 \mathrm{~cm}$. México, Museo Nacional de Historia. Conaculta-InAH-MÉx. "Reproducción autorizada por el Instituto Nacional de Antropología e Historia”.

orden. Cuatro flores de lis situadas en los entrebrazos completan el conjunto. ${ }^{56}$ Gálvez, que obtuvo el privilegio en I77I, era caballero pensionado, por lo que muestra la enseńa pendiente de un lazo textil, mientras que Güemes y De la Grúa, dotados con la gran cruz de la orden en 1792 y I79I, respectivamente, además de las placas, lucen banda terciada de seda azul celeste y bordes blancos. ${ }^{57} \mathrm{La}$ indefinición de los trazos pictóricos en los tres casos impide saber si algunas de estas encomiendas incorporaron diamantes en su decoración.

56. Bula en que N.S. Padre Clemente XIV aprueba y confirma la Real Orden Española de Carlos III; y Breve en que concede privilegio de anima al altar dedicado á la concepción de Nuestra Señora en la iglesia de San Gil de Madrid, Madrid, Imprenta Real de la Gazeta, I772; Ceremonial que se ha de observar en la función de prestar el juramento y hacer su profesión los caballeros pensionados de la Real y Distinguida Orden Española de Carlos III, en la Iglesia de San Gil de Religiosos franciscanos de Madrid, s.l., s.e., s.a.; Historia, trajes y condecoraciones de todas las órdenes de caballería e insignias de honor, Barcelona, Agencia Médica Doctor Martí y Artigas, I848, t. I, pp. 380-393; Federico Fernández de la Puente y Gómez, Condecoraciones españolas. Órdenes, cruces y medallas civiles, militares y nobiliarias, Madrid, Gráficas Osca, 1953, pp. 23-34.

57. Indice de pruebas de los caballeros de la Real y Distinguida Orden Española de Carlos III desde su institución hasta el año I847, Madrid, Archivo Histórico Nacional, I904, pp. 68 y 80-8I. 
El conde de Revillagigedo se adorna además con una venera de la orden de Calatrava a la que pertenecía, mientras el marqués de Branciforte hace lo propio con una de Santiago, si bien se trata de dos de las alhajas más sencillas de todo el repertorio que ofrece este gabinete, las cuales quedan eclipsadas además por el tamaño, la morfología y el color de las correspondientes a Carlos III.

La introducción del neoclasicismo y los cambios en los gustos y las modas acontecidos a finales del siglo XviII, pero sobre todo las nuevas leyes promulgadas en la centuria siguiente, reflejo de las convulsiones políticas que sacudieron España y afectaron profundamente el funcionamiento de las órdenes militares por la pérdida de sus bienes, tuvieron una repercusión lógica en la joyería, tal como muestran los virreyes decimonónicos. ${ }^{58}$ Nos hallamos ante un conjunto de piezas muy dispar en cuanto a calidades y diseños. Entre las más ricas, merece la pena destacarse la venera de Santiago que luce Miguel José de Azanza (I798-I80o). De estilo plenamente neoclásico, presenta un perfil oval con placa esmaltada central rodeada de una orla con una fila de diamantes de buen tamaño y un marco cuajado de la misma pedrería describiendo una guirnalda, coronándose con un pequeño copete (fig. I 4). Pero frente a ella existen otras alhajas de extremada sencillez, reducido tamaño y escasa riqueza, como el hábito de Calatrava que muestra Francisco Javier Venegas (I8IO-I8I3), donde la cruz de Calatrava aparece esmaltada sobre una simple placa oval de oro rematada por asa. Finalmente, los dos últimos virreyes (Juan Ruiz de Apodaca, I8I6-I82I, y Juan O’Donojú, I82I) no ofrecen ningún interés en cuanto a joyería se refiere, pues, vestidos de gala, lucen varias placas siguiendo el modelo de las condecoraciones militares.

\section{El Toisón de Oro}

Si pertenecer a una orden militar estaba asociado a conceptos como distinción o selección, lucir el Toisón de Oro, como lo hacían los reyes de España, significaba para un caballero el mayor de los honores, un privilegio máximo, dado su carácter absolutamente restringido al que, de acuerdo con sus constituciones de I5I6, sólo tenían acceso 5 I miembros. Fundada en Brujas por Felipe el

58. Rafael de la Brena et al., "Lux Hispaniarum: pasado, presente y futuro de las órdenes militares”, en Campos (coord.), op. cit., pp. 55-61. Ya en I809 José Bonaparte dispuso la supresión civil de las órdenes militares y la confiscación de sus bienes. 

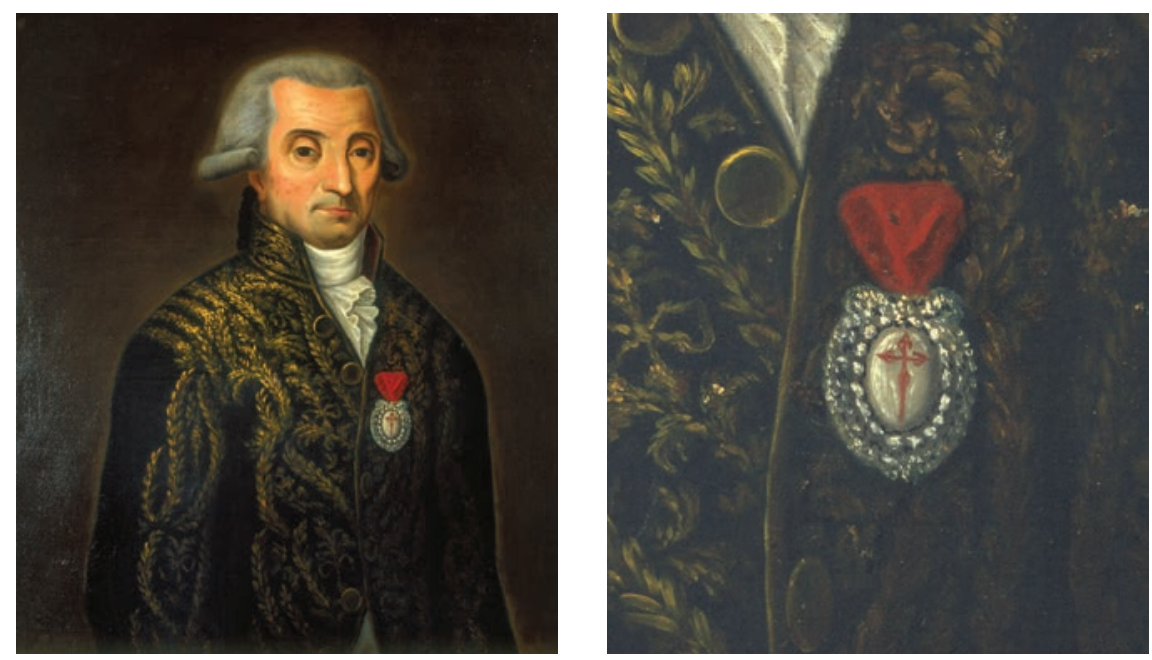

I4. Anónimo, Miguel José de Azanza, ca. I80o, óleo sobre lienzo, 94×74 cm. México, Museo Nacional de Historia. Conaculta-INAH-MÉx. "Reproducción autorizada por el Instituto Nacional de Antropología e Historia”.

Bueno, duque de Borgońa y conde de Flandes, el io de enero de I430, coincidiendo con las celebraciones de su boda con la infanta Isabel de Portugal, la orden del Toisón tuvo como objetivos principales la gloria de Dios y la defensa de la fe cristiana y la Iglesia. Bajo el patronato de la Virgen María y san Andrés, fomentaría la virtud, el honor caballeresco y las buenas costumbres, por lo que sólo se admitiría en ella a nobles de irreprochable conducta. Pero en un momento de afianzamiento y expansión del Estado borgoñón, se escondía también bajo esta fundación una finalidad política. Para generar una monarquía poderosa, el duque necesitaba crear vínculos de unión entre la nobleza de los territorios sometidos a su autoridad, de modo que propició la admisión en su consejo privado de los caballeros que formaran parte de la nueva orden.59

En el tercer artículo de sus estatutos se plasmó el emblema que se utilizaría: una piel o vellocino de carnero dorado colgando de un collar compuesto alternativamente por fusils (eslabones estilizados en forma de B entrelazadas) y pedernales de los cuales partirían llamaradas. La elección no fue casual. Eslabo-

59. Alfonso de Ceballos-Escalera y Gila, La insigne orden del Toisón de Oro, Madrid, Real Sociedad Económica Segoviana, 2000, pp. 59-69; Historia, trajes y condecoraciones de todas las órdenes de caballería..., op. cit., t. I, pp. 4-I6. 
nes, pedernales y flamas constituían la divisa personal del duque, cuya ánima decía Ante ferit quam micet (golpea antes de que surja la llama). ${ }^{60} \mathrm{La}$ riqueza y el aparato de este nuevo símbolo encajarían a la perfección con la brillantez de la corte borgoñona y su refinadísimo ceremonial.

Los reyes de España, como herederos del ducado de Borgoña, se convirtieron en los grandes maestres de esta orden, luciendo en la mayoría de los retratos una joya con el Toisón, como se observa — por citar sólo un ejemplo- en Felipe II, quien no siempre la mostró con collar metálico sino que en ocasiones la lució pendiente de un cordón negro o una cinta encarnada. Lógicamente el patrimonio real, tal como se aprecia en los inventarios, fue nutriéndose de estas piezas, llegando a ser muy extensa la colección ya en tiempos de Carlos II, con ejemplares con rica pedrería y novedades técnicas como monturas al aire o combinaciones cromáticas de las piedras. ${ }^{61}$ En el siglo XviII se alcanzarían alhajas de una riqueza extrema, añadiendo por encima del vellocino otros cuerpos o entrepiezas con abundante pedrería como lo demuestra, por ejemplo, el llamado Toisón de Carlos $\mathrm{V}$ o el ejemplar conservado en el palacio de Ajuda de Lisboa, realizado por Ambrosio Gottlieb hacia 1790 para el príncipe regente de Portugal, Juan, en el que las piedras preciosas se cuentan por cientos. ${ }^{62}$

En el caso de la galería del Museo Nacional de Historia de México, son dos los virreyes que lucen este exclusivo emblema. El primero es Pedro Nuño Colón de Portugal, descendiente del descubridor de las Indias (fig. I5). Nacido en Madrid en I628 - hijo de Álvaro Colón de Portugal y de Catalina de Portugal y Castro-, fue V duque de Veragua y de la Vega, Grande de España,

6o. Ceballos-Escalera y Gila, La insigne orden del Toisón de Oro, op. cit., pp. 65 y 77: "un collar de oro formado por nuestra divisa, que es a saber por piezas en forma de eslabones golpeando pedernales, de los que parten centellas ardientes, y en el extremo de este collar pendiente una figura de un toisón de oro." ("un collier d'or fait à notre devise, c'est à sçavoir par pieces à façon de fusils touchants à pierres dont partent estincelles ardantes, et au bout d'icelu collier pendant la semblance d'une Toison d'or"); Fernández de la Puente y Gómez, op. cit., pp. 249-253.

6I. Arbeteta Mira, La joyería española de Felipe II a Alfonso XII..., op. cit., p. 23. Sobre los ejemplares que poseyeron Carlos V y Felipe II puede verse Dolores María Mármol Marín, Joyas en las colecciones reales de Isabel la Católica a Felipe II, Madrid, Fundación Universitaria Española, 200I, pp. 220-227.

62. Isabel Silveira Godinho, Tesouros reais, Lisboa, Instituto Portugués do Património Cultural, 1992, pp. I53-I55; Gonçalo Vasconcelos e Sousa, A joalharia em Portugal, I750-I825, Oporto, Civilizaçâo Editora, I999, pp. II8-II9. 


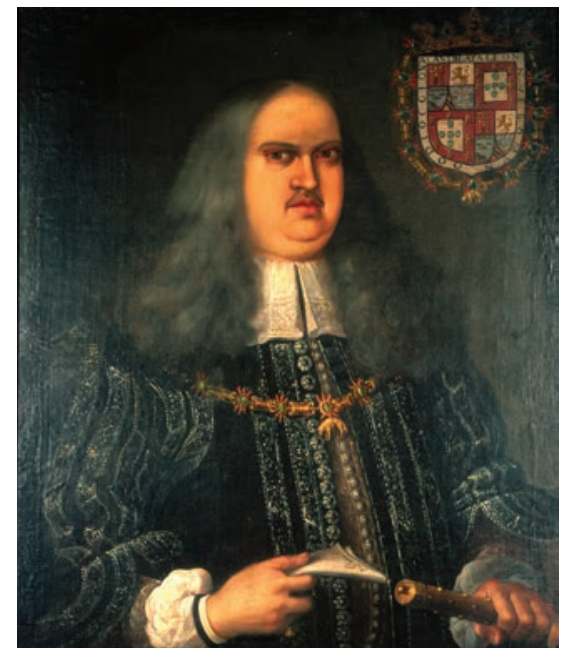

15. Anónimo, Pedro Nuño Colón de Portugal, duque de Veragua y de la Vega, I673, óleo sobre lienzo, 94×68 cm. México, Museo Nacional de Historia. Conaculta-INAH-MÉx. "Reproducción autorizada por el Instituto Nacional de Antropología e Historia”.

V marqués de Jamaica, VI conde de Guelves, III marqués de Villamizar y VII almirante y adelantado mayor de las Indias. Sirvió a la monarquía hispánica en campañas en Argel, Cataluña y Flandes como maestre de campo de infantería. Fue teniente coronel de la guardia del rey en la guerra de Portugal, capitán general de la armada de Flandes y capitán general de Mar Océano (I666). Concluyó su carrera política y militar como virrey de la Nueva España, adonde llegó en I672. Pero su gobierno fue brevísimo pues falleció cinco días después de haber tomado posesión de su cargo. ${ }^{63}$

El retrato de este Grande de España, de autor desconocido, muestra a un hombre bastante corpulento de rostro obeso, quizás enfermo, que mira directamente al espectador. Se trata de una obra que destaca entre todos los mandatarios del siglo XviI correspondientes a esta galería por la riqueza de su vestido. Frente a la austeridad de sus homónimos, Pedro Nuño viste una ropilla de terciopelo negro con amplias mangas abullonadas decoradas por ricas cenefas bordadas en hilo de plata, similares a las que se disponen verticalmente sobre la pechera de la misma prenda. Completa el traje con una valona bordada, puños blancos y un jubón que asoma bajo la ropilla. Es precisamente en estas dos últimas prendas donde se distribuyen dos largas hileras de botones labrados de plata que enriquecen el atuendo. Pero la joya más importante 


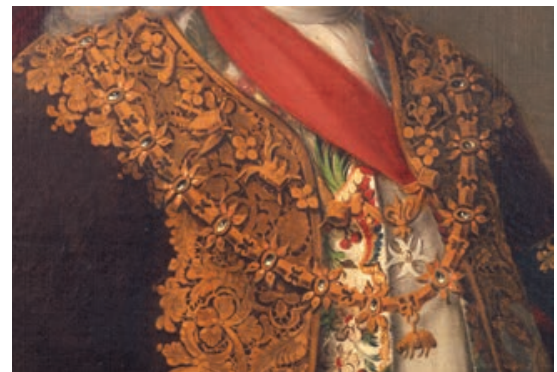

16. José de Ibarra, Pedro Cebrián y Agustín, conde de Fuenclara, I743-1746, óleo sobre lienzo, $94 \times 74 \mathrm{~cm}$. México, Museo Nacional de Historia. Conaculta-INAH-MÉx.

"Reproducción autorizada por el Instituto Nacional de Antropología e Historia”.

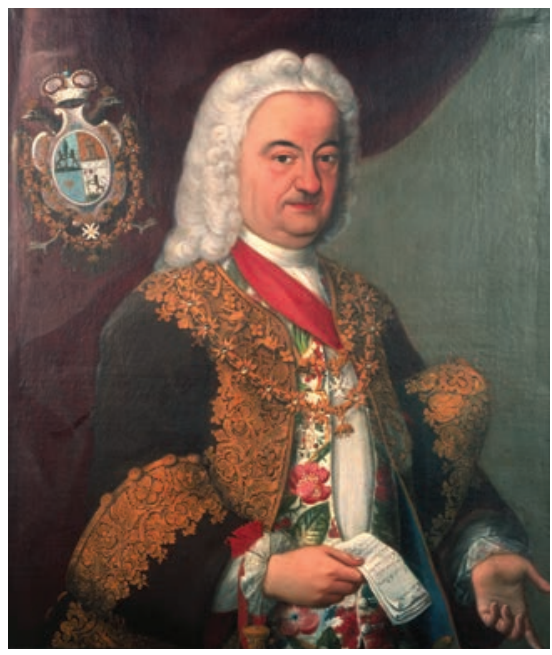

con que se adorna el virrey es lógicamente el Toisón, realizado en oro como era preceptivo, carente de pedrería, con su correspondiente collar —repetido en el escudo de armas - cuyos eslabones muestran esmaltes en azul y rojo para constituir los pedernales y las flamas necesarias. A través de esta insignia mostraba la pertenencia a una orden muy selecta para la que fue elegido como caballero el I9 de agosto de I670, si bien no fue investido hasta mayo de I67I en Cádiz por su primo Diego de Portugal, gobernador de Gibraltar. ${ }^{64}$

Mucho más interesante resulta el retrato de Pedro Cebrián y Agustín. No en vano salió de los pinceles de uno de los pintores más prestigiosos del virreinato durante el siglo XviII, José de Ibarra (fig. I6). De rostro bonachón y realista y tocado por peluca blanca, el V conde de Fuenclara, Grande de España, muestra una de las indumentarias más extraordinarias de toda la galería de retratos. Viste traje de gala con casaca oscura con abundantes bordados en hilo de oro describiendo motivos vegetales en las solapas y en los vueltos de las mangas, así como en el tricornio que sujeta bajo el brazo izquierdo. Por debajo asoma una chupa blanca también bordada con grandes flores y hojas en colores vistosos, tela probablemente de origen asiático llegada en el galeón de Manila. Nos hallamos ante el virrey que logró las mayores distinciones de manos reales, tal como atestigua su retrato, en virtud de los

64. Ibidem, p. 365. 
importantes servicios prestados a la monarquía. En efecto, Cebrián y Agustín se adorna con dos collares sobre sus hombros y sus respectivas insignias. Una corresponde a la orden de San Jenaro y la otra a la del Toisón de Oro, las más importantes del reino de las Dos Sicilias y de España respectivamente, gracias que le fueron concedidas en 1738 y cuya imposición corrió a cargo del propio Carlos VII de Nápoles, futuro Carlos III de España. No debe sorprender su relación con el reino napolitano, pues a Fuenclara se debió en gran medida el matrimonio del mencionado monarca con María Amalia de Sajonia. En efecto, después de haber desempeñado tareas diplomáticas en Venecia, Felipe $\mathrm{V}$ le encomendó negociar el matrimonio de su hijo. Para ello fue enviado a Viena en I736, pues se pensó en María Ana de Habsburgo como futura esposa, pero fracasadas las negociaciones en la corte austriaca, pasó a Dresde en 1738 para concretar el enlace matrimonial con la hija de Federico II de Sajonia y III de Polonia, María Amalia. Como recompensa a su buen hacer en aquella misión, el monarca español le concedió el Toisón de Oro el 8 de enero de aquel año, si bien no sería investido hasta el I2 de julio. Fue también Pedro Cebrián y Agustín el encargado de conducir la comitiva que habría de llevar a la nueva reina hasta Nápoles, donde hizo su entrada el 2 de julio de 1738 , quedando como embajador en aquella ciudad y como mayordomo del infante Felipe. Un día después de la llegada, Carlos VII fundó la Real Orden de San Jenaro y nombró a Fuenclara caballero de la misma, gracia que vino a sumarse al Toisón otorgado por Felipe V. ${ }^{65}$ Reclamado en España llegó a Madrid en julio de I740, donde permaneció hasta I742, momento en que fue nombrado virrey de la Nueva Espańa y presidente de su audiencia. ${ }^{66}$

El Toisón que luce en el lienzo pende de una sencilla argolla del collar de oro cuyos pedernales muestran cierto brillo que probablemente se corresponden con esmaltes en tonos grisáceos, similares a los ejemplares del siglo XVIII que han llegado hasta nuestros días, como el conservado en una colección particular de Lisboa que perteneció al rey Miguel de Portugal, quien probablemente lo heredó de su padre Juan VI.67 La misma técnica del esmalte parece ser la utilizada en el color rojo de las flamas, aunque no podemos per-

65. Ceballos-Escalera y Gila, Historia, trajes y condecoraciones de todas las órdenes..., op. cit., t. I, pp. 84-85.

66. Sergio Castillo Espinosa, Don Pedro Cebrián y Agustin: V conde de Fuenclara, virrey de Nueva España, Borja, Institución Fernando el Católico, 1995; Ceballos-Escalera y Gila, La insigne orden del Toisón de Oro, op. cit., pp. 43 I-432.

67. Silveira Godinho, op. cit., pp. I56-I59. 
der de vista que en los ejemplares más ricos, normalmente ligados a la familia real, también se emplearon rubíes. Es probable que este Toisón, carente de pedrería, se corresponda con el que el monarca entregaba numerado al nuevo caballero cuando lo armaba y el cual debía ser devuelto a su muerte. Pero este virrey fue propietario al menos de otra alhaja de este tipo, pues en su testamento consta la presencia de un toisón guarnecido de diamantes que dejó como herencia a su hijo político Antonio de Silva. ${ }^{68}$

De menor tamaño, y por tanto colocado por encima del anterior, resulta el collar de hombros de San Jenaro, del que pende la correspondiente cruz griega de brazos ahorquillados, recortada y esmaltada en blanco. En el centro se intuye la preceptiva imagen del santo obispo mártir. El retratado se adorna también con una banda roja, propia de esta orden fundada por Carlos VII, quien continuó siendo gran maestre de la misma cuando se convirtió en Carlos III de España, lo que pone de manifiesto la estrecha relación de esta institución con la Corona española. De las I4I concesiones que se hicieron entre I738 y 1759, 57 fueron caballeros españoles y el marqués de Fuenclara se encontró entre los primeros. ${ }^{69}$ El collar de oro que exhibe está formado por diversos tipos de eslabones. El central es una flor de lis y el resto son flores cuadripétalas que alternan con otros eslabones de variados motivos, como las ampollas con la sangre de San Jenaro sobre palmas, un báculo de obispo con un cáliz y el Santísimo Sacramento, una mitra con una bandera y una espada, así como un tambor con banderas. ${ }^{70}$

68. Castillo Espinosa, op. cit., p. I3 I.

69. Sobre la orden de San Jenaro puede verse marqués de Villarreal de Álava, La Maison royale des deux Siciles. L'Ordre Constantinien de Saint Georges et l'Ordre de Saint Janvier, Madrid, Altamira Gráficos, 1964, pp. 465-475. Más recientemente, Guy Stair Sainty, The Orders of Chivalry and Merit of the Bourbon Two Sicilies Dynasty, Madrid, 1989; Alfonso de Ceballos-Escalera y Gila, España y las órdenes dinásticas del reino de las Dos Sicilias, Madrid, Real Sociedad Económica Segoviana, 2000.

70. El collar preceptivo de la orden de San Jenaro está formado por eslabones con la flor de lis que alternan con otros como la C (de Carlos) sobre banderas y palmas, una torre castellana sobre banderas cruzadas, un evangelio abierto con dos ampollas de la sangre del mártir, un báculo con el cáliz y el Santísimo Sacramento y, en la parte posterior, un león sobre banderas cruzadas. 


\section{Otras joyas}

Tal como hemos comprobado, durante varios siglos los hábitos militares fueron las joyas más extendidas para el adorno masculino. Sin embargo, hubo también otras tipologías que, aunque en menor medida, quedaron reflejadas en esta galería mexicana de retratos.

Herederos de la Edad Media, los botones fueron piezas que a lo largo del siglo XVI hombres y mujeres emplearon con profusión, tanto para sujetar la indumentaria cuanto como elemento de adorno, colocándolos en fila y normalmente sobre costuras. Aunque podían presentar diseños diversos e incorporar esmaltes, pedrería o perlas, como muestran el inventario de bienes de Felipe II, los exámenes barceloneses y numerosos retratos del siglo XVI y principios del siglo XVII, ${ }^{7 \mathrm{I}}$ los más habituales en la primera mitad del siglo XVII, como ocurre en las efigies de los virreyes, fueron los botones redondos de oro. Su paralelo femenino en México lo encontramos en el retrato de una dama atribuido a Baltasar de Echave Ibía, exhibido en el Museo Nacional de Arte (México). ${ }^{72}$ Dispuestos sobre el eje central de la ropilla negra, algunos mandatarios también los lucieron en sus ferreruelos, como el marqués de Cerralbo (fig. 2) o el marqués de Villena (fig. I7), dando color y aportando suntuosidad a aquella moda tan severa. El detallismo en la pintura del marqués de Villena permite comprobar que todos los botones que exhibe sobre su indumentaria son similares: perfil redondo, a modo de flor de ocho pétalos, en cada uno de los cuales se aloja una esfera, como ocurre también con el espacio central, cuyo resalte puede corresponderse con otra esfera o quizá con un diamante engastado.

La factura de estas piezas en muchas ocasiones pudo ser americana, pues se producían en abundancia en los virreinatos, e incluso de Asia, desde donde arribaban ejemplares de filigrana. Así lo atestiguan los hallados en los pecios de diversos galeones, entre los cuales no faltaron tampoco los que se decoraban con esmaltes o gemas. ${ }^{73}$ En la segunda mitad del siglo XviI, este tipo de botones desapareció en la indumentaria de los virreyes - excepto en la del duque de Veragua-, dando todo el protagonismo a las encomiendas.

71. Muller, op. cit., pp. 98-99; Mármol Marín, op. cit., pp. 202 y 205-208.

72. Ruiz Gomar, op. cit., p. II, considera que, dada la elevada calidad de esta obra, hay que reconsiderar la actual atribución y quizá otorgársela a Echave Orio.

73. Arbeteta Mira, "Joyas en el México virreinal: la influencia europea”, op. cit., pp. 427428. 
17. Anónimo, Diego López Pacheco, marqués de Villena, ca. I640, óleo sobre lienzo, $93 \times 70 \mathrm{~cm}$. México, Museo Nacional de Historia. Conaculta-InAH-MÉx.

"Reproducción autorizada por el Instituto Nacional de Antropología e Historia”.

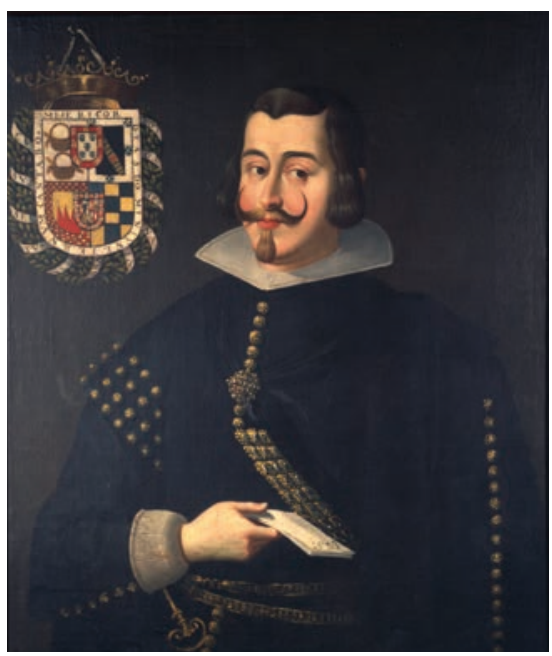

Pero de nuevo en el siglo XVIII se volvieron a recuperar. Con un carácter más práctico estaban destinados a abrochar las casacas y las chupas, por lo que se lucieron en menor número, si bien fueron ejemplares, en general, de mayor tamaño, semiesféricos y en oro y plata.

Empleadas desde finales del siglo XVI, durante los reinados de Felipe III y Felipe IV se generalizó en el ámbito masculino el uso de gruesas cadenas o bandas de oro. El que estuvieron muy de moda durante buena parte del siglo XVII se aprecia hasta en cuadros de temática religiosa, como el san Alejo que pintó José Juárez en 1653, conservado en el Museo Nacional de Arte de México, donde un cofre abierto deja ver, entre las numerosas alhajas que contiene, varias cadenas metálicas de grandes eslabones, así como collares con cuentas de perlas, muy abundantes en la joyería de la Nueva España. Como se comprueba en varios retratos de la galería de Chapultepec, los hombres lucían estas bandas terciadas, colgando desde el hombro derecho hasta la cadera izquierda. Muchas de estas alhajas salieron de talleres situados en las Indias, tanto occidentales como orientales, pues así lo vuelven a atestiguar una vez más las piezas extraídas de algunos pecios. Las hubo de gruesos eslabones macizos, a veces entorchados, como la hallada en el galeón Nuestra Señora de Atocha y conservada en el Museo de América de Madrid. Pero no faltaron tampoco las de filigrana, llegadas a través del galeón de Manila, cuyo éxito radicó en su escaso peso y gran apariencia. Aunque tradicionalmente se pensaba que 
procedían de China, en sus últimos estudios Arbeteta considera estas cadenas de filigrana originarias de la India. De allí serían no sólo las encontradas en el galeón Nuestra Señora de la Concepción, hundido en 1638, que pueden verse en el Instituto Valencia de Don Juan, sino también las piezas que lucen numerosos retratos de la época, como los correspondientes a Felipe IV (en el Metropolitan Museum de Nueva York), al conde duque de Olivares (en la Hispanic Society de Nueva York), realizados por Velázquez en I624, o al marqués de Leganés, ejecutado por Van Dyck hacia I634 (en la Fundación Banco Santander). ${ }^{74} \mathrm{El}$ paralelismo en la galería mexicana lo hallamos en la banda de gruesos eslabones que exhibe Rodrigo Pacheco y Osorio en su retrato de I624 (fig. 2). La tosquedad en el trazo de la pintura impide determinar si se trata de una cadena maciza o si, por el contrario, responde a modelos en los que se emplea la técnica de la filigrana. No obstante, sea cual sea la técnica utilizada, la coincidencia cronológica de este retrato con la del monarca y su valido permite comprobar sin duda alguna la vigencia, en fechas similares, de las mismas modas en la joyería a uno y otro lado del Atlántico. Una tercera variante de banda la luce el marqués de Cadereita, formada por eslabones de oro cuadrilobulados calados.

No obstante, el retrato más interesante y rico en cuanto a este tipo de joyas resulta el de Diego López Pacheco, marqués de Villena (I640-I642) (fig. 17). Realizado hacia I640, luce una gran cadena reticulada formada por una triple hilera de botones rectangulares con el perfil enmarcado por cenefa perlada. Cada una de las piezas presenta un diamante-tabla engastado. Pero además de los botones mencionados antes y la cadena, este virrey se adorna con una joya de perfil mixtilíneo sobre el pecho, cuajada de diamantes engastados en oro, y con un cinturón de dos vueltas de tejido metálico. Es éste el único virrey que luce en la galería de retratos este tipo de pieza realizada toda ella en oro. Aunque hay otros mandatarios que portan cinturones, resultan mucho más sencillos y en ellos sólo la hebilla es metálica, de plata, como el del conde de Alba de Aliste, que presenta un diseño a base de ces. Volviendo al marqués de Villena, es necesario señalar como último complemento de su atuendo y

74. Muller, op. cit., p. Iıо; Arbeteta Mira, La joyería española de Felipe II a Alfonso XII..., op. cit., pp. 50 y I38; "La joyería: manifestación suntuaria de los dos mundos", op. cit., pp. 428429, 442 y 704-705; "Joyas en el México virreinal: la influencia europea”, op. cit., pp. 428-430; "Influencia asiática en la joyería española. El caso de la joyería india", op. cit., pp. I23-I46; "Las joyas en el retrato virreinal: una aproximación a su estudio", op. cit., pp. 46-47; Concepción García Sáiz, "Fragmento de cadena”, en Iglesias (dir.), op. cit., p. 340. 
adorno una llave honorífica que porta a la altura de la cintura y que simbolizaría, según Moya, el gobierno de la ciudad de México. Aunque quizá pudiera ser de oro, parece más probable que tanto este ejemplar como el que llevan otros virreyes del siglo XVII, como el conde de Alba de Aliste y el duque de Alburquerque, hubieran sido realizados en hierro forjado y cincelado y posteriormente dorados al fuego, como las llaves conservadas en el Museo Antropológico Nacional de Madrid, símbolo éstas de gentilhombre de cámara de su majestad, y por tanto de poder y autoridad en la corte, así como de proximidad al rey. ${ }^{75}$

Otras piezas suntuosas con las que posaron varios virreyes novohispanos en sus retratos fueron espadas y bastones de mando, las primeras en el siglo XVII y los segundos desde mediados del Siglo de las Luces y en el siglo xix. Fue habitual a lo largo del antiguo régimen que los caballeros hispanos tuvieran en sus ajuares espadas, espadines, dagas, puñales y bastones con empuñaduras de metales preciosos, a veces con piedras preciosas engastadas, tal como se deduce de múltiples inventarios de bienes, riqueza que se extendía a menudo a sus sillas de caballo, espuelas y guarniciones. Sirva como ejemplo el inventario de bienes de José Armendáriz y Perurena, marqués de Castelfuerte, que fue virrey de Perú (1733-I749), donde figuran varias de las tipologías mencionadas. ${ }^{76}$ En la galería mexicana, todos los virreyes civiles del último cuarto del siglo XVII, excepto el conde de Moctezuma, así como el primero del siglo XVIII, duque de Alburquerque, lucen, asidas a la cintura, espadas que las pinturas muestran de color plateado. Aunque es muy probable, dada la calidad de sus portadores, que sus empuñaduras fueran de plata, no podemos descartar que estuvieran realizadas íntegramente en acero.

Por su parte los bastones, desde la Prehistoria, se habían erigido en símbolo de autoridad, en distintivo de mando. Ya en la Edad Moderna sus portadores los mostraban ante la sociedad como enseña o signo de poder, de potestad, de jerarquía y jurisdicción. Estos atributos, formados por caña de madera y puño y contera de metal, aparecen en los retratos virreinales, como era preceptivo en el principal representante del monarca y máxima autoridad militar, con empuñadura de oro, probablemente de chapa cincelada y repujada. Aun-

75. Sanz Ayán, "Dos llaves honoríficas de gentilhombre", en Iglesias (dir.), op. cit., p. 339.

76. Pilar Andueza Unanua, "Nuevas piezas de platería civil hispanoamericana a la luz de los inventarios de bienes", en Paniagua Pérez y Salazar Simarro, Ophir en las Indias..., op. cit., pp. $482-483$. 
que apenas pueden apreciarse los detalles de las empuñaduras pues están en gran medida cubiertas por la mano de su portador, se comprueba su evolución que progresivamente va pasando de un tamaño pequeño con perfil periforme hacia modelos más alargados, troncocónicos y de líneas más rectas. Sólo en el caso del ejemplar que porta Pedro Cebrián y Agustín, conde de Fuenclara, se aprecia el engaste de diamantes.

\section{Las joyas de los obispos}

Entre los virreyes que gobernaron la Nueva España hubo io obispos o arzobispos que rigieron de manera interina el destino de aquellas tierras. Como es propio en esta categoría de prelados, en sus retratos aparecen con dos insignias episcopales: cruz pectoral y anillo, ofreciendo una gran variedad de modelos especialmente en lo que a cruces se refiere. Sólo Pedro Moya de Contreras (1584-1585) añade a su imagen un báculo de plata de cañón entorchado, rematado con cruz griega dorada de brazos florenzados.

Aunque los anillos o sortijas nacieron como adorno para los dedos, en ocasiones eran además portadores de determinados valores. Es el caso de los anillos episcopales, auténticos emblemas de la autoridad eclesiástica y sobre todo, desde antiguo en España, símbolo de los desposorios místicos entre el obispo y su Iglesia, que se lucían en el dedo anular derecho. ${ }^{77}$ Lamentablemente la escasa calidad de los retratos y el pequeño tamaño de este tipo de joya hacen que su detallismo en estas pinturas sea mínimo, lo que apenas permite describirlos y aún menos extraer conclusiones. No obstante, podemos afirmar que todos los ejemplares que muestra esta galería son anillos con un gran chatón central en el que se engasta, bien de manera rectangular o circular, una única piedra preciosa. En algunas ocasiones resultan de gran sencillez, como ocurre con el rubí oval que luce Diego Osorio de Escobar (I664); sin embargo, en otras las piedras preciosas fueron engastadas sobre monturas de más desarrollo, como se aprecia en Marcos de Torres (I648-I649), que incorpora cartones recortados, o Payo Enríquez de Ribera (I673-1780), que ofrece un enmarque de oro más elaborado. Como pieza de mayor riqueza cabe mencionar el ejemplar de Francisco Javier Linaza (I809-I8Io) que parece portar un topacio orlado de diamantes. 
Las cruces pectorales de los obispos, por su simbolismo, fueron siempre de gran tamańo, similares en este sentido a las que empleaban las damas, como joyas devocionales y con carácter protector, en el siglo xvi. Excepto el pectoral de oro que luce Juan de Palafox, que carece de pedrería pero incorpora al Crucificado, y muy probablemente también reliquias, ${ }^{78}$ todos los ejemplares que muestran los prelados del siglo XVII en esta galería siguen una misma estructura: cruz latina con el anverso ocupado por cajas de engaste en las que se alojan piedras preciosas, talla-tabla de perfil cuadrado y rectangular. Tanto en los ejemplares de fray García Guerra (I6I I-I6I2) y Marcos de Torres y Rueda (I648-I649) como en el de Diego Osorio de Escobar (I664), son I I las piedras que se reproducen, si bien no podemos concretar el tipo de gema empleado. Atendiendo a ejemplares que han llegado hasta nuestros días, podría tratarse de esmeraldas o diamantes, aunque tampoco podemos descartar el cuarzo, pues, dadas las características claras y transparentes del cristal de roca, fue piedra empleada con abundancia en la joyería y más concretamente en las cruces pectorales. Entre todos los ejemplares de la centuria mencionada, merece la pena destacarse por la nitidez con que está reproducido el pectoral que luce Diego Osorio de Escobar. En su retrato, realizado hacia I664, este obispo de Puebla de los Ángeles viste roquete y capa magna y porta un breviario en su mano con cantoneras metálicas. Su pectoral sigue el modelo descrito y está rematado por perinolas torneadas de tres cuerpos decrecientes.

Por su parte, entre los prelados del siglo XviII sobresale el retrato del arzobispo de México, Alonso Núnez de Haro y Peralta, realizado hacia 1787 por autor desconocido (fig. I8). Luce una joya de gran aparato que destaca sobre la muceta de raso negro. Se trata de una cruz latina compuesta por cinco rubíes ovales de gran tamaño (dos en el brazo largo y uno en cada brazo corto) y uno circular en el cuadrón. La cruz cuelga de un copete en el que se engasta otro

78. Palafox poseyó varios pectorales, unos de metales preciosos, pero también otros mucho más sencillos de cristal y hueso. Según sus Direcciones pastorales, estas piezas podían carecer de pedrería, pero siempre debían llevar reliquias, pues éstas influirían en los aciertos espirituales del pastor. Entre los que fueron de su propiedad hubo uno de oro con la Pasión grabada y otro de cristal de roca con remates de oro. Otros fueron a parar a diversas catedrales espańolas y novohispanas o a la abadía de Montserrat y al final de sus días legó otro a su amigo el cardenal de Toledo Baltasar Moscoso; véase Ricardo Fernández Gracia, Iconografía de don Juan de Palafox. Imágenes para un hombre de Estado y de Iglesia, Pamplona, Gobierno de Navarra, 2002, pp. I50-I5 I, y, del mismo autor, Don Juan de Palafox. Teoria y promoción de las artes, Pamplona, Asociación de Amigos del Monasterio de Fitero, 2000, p. 310. 

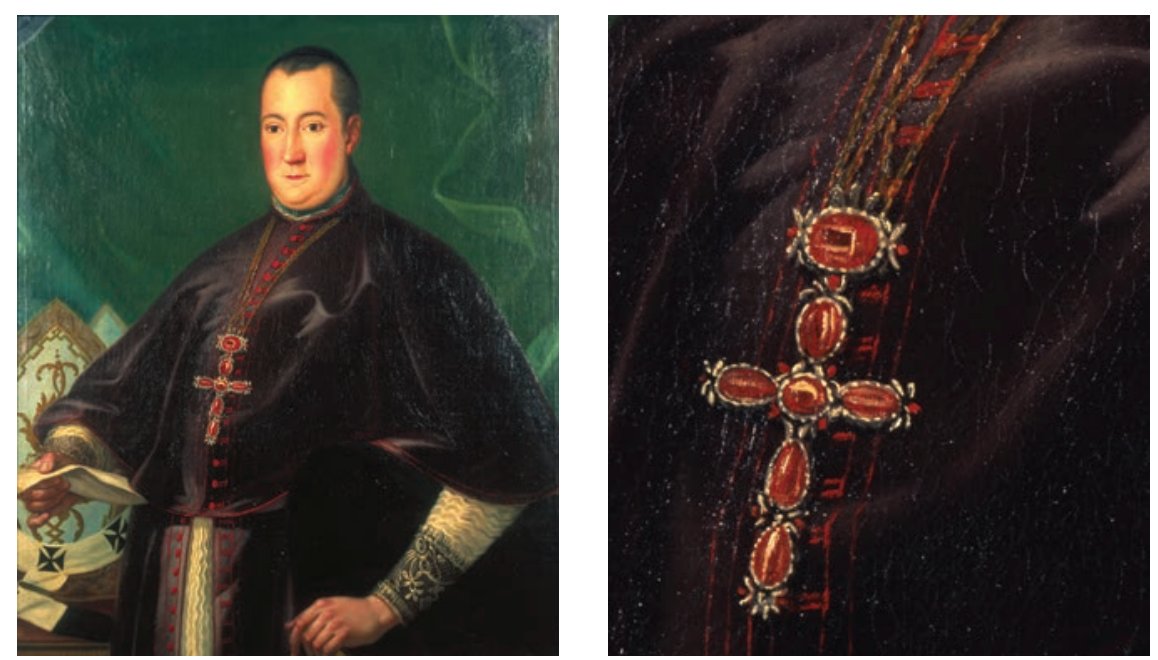

I8. Anónimo, Alonso Núñez de Haro y Peralta, arzobispo de México, ca. I787, óleo sobre lienzo, $93 \times 75 \mathrm{~cm}$. México, Museo Nacional de Historia. Conaculta-InAH-MÉx. "Reproducción autorizada por el Instituto Nacional de Antropología e Historia".

rubí facetado. Este ejemplar permite comprobar la gran evolución sufrida por los engastes, pues si en el siglo XVII madame D’Aulnoy denunciaba la impericia de los joyeros espańoles en el montaje de las piedras, en el XVIII se dio paso a engastes mucho más airosos donde las gemas lucían con todo su esplendor, como ocurre con este ejemplar. ${ }^{79}$

Finalmente, Francisco Javier de Linaza, arzobispo de México y virrey entre I809 y I8Io, porta sobre su pecho una cruz pendiente de un cordón textil sujeta con un botón pasador a juego. Es una cruz latina de plata con los brazos recorridos por engastes de pedrería, posiblemente topacios, a juego con el anillo, y terminaciones de ces vegetales, similares a modelos que han perdurado hasta nuestros días.

Ésta ha sido, en suma, una aproximación a las joyas que lucieron los virreyes de la Nueva España. La conservación íntegra de la galería de retratos custodiada en el Museo Nacional de Historia de México nos ha permitido acercarnos a los mandatarios que rigieron la Nueva España a través de 
sus joyas, complementos imprescindibles en la proyección de su imagen y apariencia pública. La secuencia completa de todos los virreyes, fuente iconográfica de primera magnitud, nos ha otorgado además la posibilidad de analizar el uso, la morfología y la evolución de estas alhajas, cuyos valores materiales y simbólicos las convirtieron en elementos fundamentales del adorno masculino. \$

N.B. Este trabajo forma parte del proyecto de investigación Imagen y Apariencia (08723/ phCs/o8), financiado con cargo al Programa de Generación de Conocimiento Científico de Excelencia de la Fundación Séneca-Agencia de Ciencia y Tecnología de la Región de Murcia en el marco del II PCTRM 2007-Io.

* Artículo recibido el 27 de febrero de 201 i; aceptado el 27 de mayo de 201 I. 